Review

\title{
Social, Economic, and Institutional Configurations of the Industrial Symbiosis Process: A Comparative Analysis of the Literature and a Proposed Theoretical and Analytical Framework
}

\author{
Emilia Faria $^{1, *(\mathbb{D})}$, Armando Caldeira-Pires ${ }^{2}(\mathbb{D})$ and Cristiane Barreto ${ }^{1}$ (D) \\ 1 Sustainable Development Center, University of Brasília, Brasília 70910-900, Brazil; crisgbarreto@gmail.com \\ 2 Mechanical Engineering Department, University of Brasília, Brasília 70910-900, Brazil; armandcp@unb.br \\ * Correspondence: emiliaofaria@gmail.com
}

check for

updates

Citation: Faria, E.; Caldeira-Pires, A.; Barreto, C. Social, Economic, and Institutional Configurations of the Industrial Symbiosis Process: A Comparative Analysis of the Literature and a Proposed Theoretical and Analytical Framework. Sustainability 2021, 13, 7123. https:// doi.org/10.3390/su13137123

Academic Editor: Paolo Rosa

Received: 22 May 2021

Accepted: 11 June 2021

Published: 25 June 2021

Publisher's Note: MDPI stays neutral with regard to jurisdictional claims in published maps and institutional affiliations.

Copyright: (c) 2021 by the authors. Licensee MDPI, Basel, Switzerland. This article is an open access article distributed under the terms and conditions of the Creative Commons Attribution (CC BY) license (https:/ / creativecommons.org/licenses/by/ $4.0 /)$.

\begin{abstract}
This paper aims at comparatively analyzing the IS process in three remarkable empirical cases. Ostrom's Institutional Analysis and Development framework and its categories for analysis are used to understand each process. A theoretical and analytical framework is proposed based on a survey of contextual elements that shaped the behavior of organizations towards Industrial Symbiosis practices. The results show that although there was no clear, linear order in which the actors developed symbiotic relationships, the decisions related to Industrial Symbiosis are shaped by a similar set of variables. These variables range from technical and economic aspects, such as the diversity of industries and the viability of exchanges, to social and institutional aspects, encompassing critical environmental issues; bilateral agreements; collective engagement; trust to build cooperative relationships; communication and information sharing strategies; integrated regulatory framework at three levels; congruence between government and company actions to create a cooperative environment; and governance structures involving local government, companies, research and development institutions, and a coordinating entity or the champion. This framework may serve as a reference for diagnostic analyses assessing aspects that can be improved wherein Industrial Symbiosis is already underway. It may also be useful in prescriptive analyses assessing the potential for implementing IS.
\end{abstract}

Keywords: industrial ecosystems; industrial symbiosis; industrial ecology; circular economy; ostrom's institutional analysis and development framework; Kalundborg; Ulsan; Kwinana

\section{Introduction}

New development models such as the Circular Economy (CE), Bioeconomy, and Industrial Ecology (IE) have emerged in response to a dominant paradigm strictly geared towards economic efficiency. These models share the same ideal: to increase integration between economic and ecological systems and reconcile economic, environmental, and social objectives [1-3].

Despite these new approaches and their increasingly widespread practices, many industrial procedures and routines are still based on unsustainable practices. The complexity and uncertainties involved in testing and implementing new concepts, procedures, and technologies to models or habits that have already been consolidated economically and culturally are often viewed with skepticism. The transition from an unsustainable industrial model to a viable industrial ecosystem requires changing the foundations of the current development model. In addition to technological and scientific advances, this transformation certainly takes time, convincing and involving various actors, and, above all, adapting the regulatory mechanisms that govern each individual's ethics and the rules that condition conduct in society [4-7]. 
Industrial Symbiosis (IS), a subset of IE, has emerged as a new industrial model capable of addressing these issues. Analogous to the biological ecosystem in its characteristics of integration and cycle of matter, IS supports the idea that waste from one industrial process can serve as raw material for another and, thus, reduce industry impact on the environment. Furthermore, it is a holistic approach as it considers the entire chain of interactions between energy, materials, and the environment [8-11].

In recent decades, a growing number of studies have evaluated the application of IS models [12]. The major emphasis of these studies is on developing methods and indicators to quantify the economic, environmental, and, to a lesser extent, the social impacts of material and energy flows resulting from human activities [13-16]. The impacts of IS practices are positive. The European Union (EU) [17] and the National Industrial Symbiosis Programme (NISP) [18] present expressive data related to the decrease in the amount of waste dumped in landfills, in the use of virgin raw materials, and $\mathrm{CO}_{2}$ emissions; the lower costs of disposal, storage, and transportation; and the revenue generated by additional sales.

Case studies focused on certain industrial sectors, such as iron/steel, cement, and waste from electrical and electronic equipment (WEEE), present good examples of facilityscale IS development. The European steel sector has made efforts to decrease $\mathrm{CO}_{2}$ emissions and improve by-product recovery and quality using technology and innovative, sustainable solutions. As a typical process industry, the steel industry has specific advantages for adopting IS because the transformation of materials is a standard part of operating procedures [19-21]. The cement sector also contributes to massive $\mathrm{CO}_{2}$ emissions, but its impact can vary significantly between different production systems and different types of cement products. There are benefits related to the reduction of $\mathrm{CO}_{2}$ emissions and conservation of natural resources resulting from IS practices in the cement sector [22,23]. In the WEEE sector, only a small percentage of waste is properly treated and recovered. By adopting IS models, materials and components could be remanufactured or reused for different products and applications [24].

Given this abundant production and recognition of the positive impacts of IS, a question remains: Why have IS practices not been widely adopted? Cohen-Rosenthal [25] argues that knowledge about the types of waste streams and their benefits alone is not enough to determine the establishment of these connections. There are social idiosyncrasies tied to political, managerial, and cultural issues, among others, that can influence the decision to adopt these industrial practices or not, and this is the reason why it is important to emphasize the social processes that shape this decision. It is not possible to dissociate the adoption of symbiotic practices from their particular context [7,26,27].

Accordingly, there have been recent research efforts to verify the main drivers and barriers to the progress of IS. A list of factors points to the relevance of economic, technical, and social relations; regulation; and culture [12,28-34]. Despite the importance of these studies to a broader understanding of the IS phenomenon, most analyses are static [35]. They focus on a single case, making it difficult to build an ample, more thorough understanding of the conditions required for organizations to adopt this new model in an effective way [26,36,37].

Therefore, we have selected three successful cases relevant to the literature on IS for an extensive examination. As an analysis tool, we chose the Institutional Analysis and Development (IAD) framework as it provides a logical structure for analyzing dynamic situations wherein individuals develop new rules, standards, and technologies [38].

Considering the potential contribution of a comparative analysis of IS initiatives, we pose the following research question: how did the implementation processes for the industrial ecosystems in the industrial parks of Kalundborg, Denmark; Ulsan, South Korea; and Kwinana, Australia arise? In answer to this question, we intend to fulfill two objectives: analyze the implementation process for IS in each case by identifying its contextual elements and propose a theoretical and analytical framework based on the convergences and similarities found in the three cases. 
To address this question, this paper has been divided into five sections, aside from this introduction, where we: (1) present the literature on IS and focus on the factors that lead organizations to adopt IS practices; (2) explain our methodology; (3) follow the implementation process for IS in each of the selected cases and list their contextual elements; (4) discuss the overall scenario observed from our comparative analysis of the cases; and (5) provide our final considerations.

\section{Theoretical Framework}

Over thirty years have gone by since the characterization of Kalundborg's IS in 1989. The case became a benchmark for sustainable industrial development based on by-product exchanges and service sharing [39]. Meanwhile, much of the literature has focused on the technological aspects to support the relevance of IS practices [4]. However, studies that go beyond the limits of the exact sciences have been gaining ground in IE through the integration of technical, economic, environmental, and social dimensions in their analysis.

The definition of IS itself has also changed due to this new perspective. Initially, Chertow [9] conceptualized IS as the engagement of traditionally separate industries through physical exchanges of materials, energy, water, and by-products to create a competitive advantage. Collaboration and synergistic possibilities offered by geographical proximity were identified as the key factors for the phenomenon. In 2012, Lombardi and Laybourn [40] proposed modifying the concept provided by Chertow [9]. They defined the essence of IS as the involvement of several organizations in a network to promote eco-innovation and long-term cultural change. In this definition, the inclusion of innovation and culture demonstrates an expansion of the notion of IS.

In this study, as well as in Boons et al. [36], we decided to treat IS as a complex social process wherein different industrial actors identify the potential of their underutilized resources and connect their flows of secondary materials, water, energy resources, services, infrastructure, and technology. This interaction between actors in mutually beneficial transactions from an economic and environmental standpoint can trigger the mobilization of intangible assets such as intellectual and social capital and create a collaborative culture as a consequence. Within this concept, there are several arrangements for IS materialization, such as eco-industrial parks (EIP), virtual IS networks, and industrial ecosystems.

Empirical research has been conducted throughout various parts of the world to identify the factors that determine the formation of these arrangements. Upon analyzing three IS cases in the United Kingdom in their early stages of implementation, Mirata [41] failed to establish common factors of success for developing IS. However, the author noted the relevance of some factors, such as the companies' operational nature and industrial history, peer pressure, and the role of the coordinating body for IS. Heeres et al. [42] examined six EIP projects in their early stages of development, three from the Netherlands and three from the United States. The results indicated that the Dutch projects were more successful than the American projects. This difference was attributed to the companies' greater participation and involvement and the presence of an association, such as a communication platform. In Kalundborg, Jacobsen [43] also found that its social context based on close personal relationships contributed to fewer technical and economic uncertainties related to IS implementation.

These findings indicate the relevance of social relationships to the consolidation and success of IS projects. The presence of an agency, an association, a council, or even one of the park's industries, which are responsible for promoting and coordinating social interactions, is now considered a catalyst for this process. Roberts [44] supports this idea by looking into creating an EIP in Queensland, Australia. A team responsible for disseminating the concept of an EIP, integrating industrial actors, and involving the community, government, and industrialists in the process was essential to the initiative's success.

Additionally, Hewes and Lyons [45] assessed the importance of a person with technical knowledge, a city authority, or a community leader responsible for conducting the IS process. The champion, as the literature refers to this figure, has partnering skills and 
obtains local support to leverage IS. In an ethnographic study by the authors on an EIP in Massachusetts and Ukraine, they identified that the key factors for the projects' viability were the champion, trust, introduction into the community, and geographical proximity.

Despite the consensus established over the years on the significance of certain factors in the materialization of the concept of IS, some of them have been questioned. Based on the experiences of NISP - a national IS program promoted by the UK government- the variables geographic proximity and familiarity among members were not found to be decisive. The need for both geographical and social proximity was resolved by the agency (NISP) upon taking the responsibility to identify synergies and calculate the economic viability of exchanges $[40,46]$. Thus, other variables were considered more relevant, such as institutional context, governance structures, and solid commercial opportunities [40,47].

However, Jensen et al. [48] note that two characteristics played a significant role in NISP's effective performance. First, a consultant proposed and facilitated the agreements. Second, adherence to the program was voluntary, and no revenue was charged for services identifying opportunities. In other words, there were no costs for participation, and adherence to the program already signaled the companies' desire to cooperate.

In the face of entities such as NISP and the champion as catalysts of IS, authors such as Domenech and Davies [37] dispute the possibility of fomenting a culture of cooperation based on these mechanisms and question the role public actors could play in conducting IS projects. As a result, authors began to incorporate social network analysis in area studies to clarify these questions and verify the correlation between IS and the structure for the network of actors, communication, and shared standards.

Studies conducted in Puerto Rico found positive correlations in Barceloneta's park between the variables, personal relationships, the actor's position in the network, and synergies. In Guayama, Puerto Rico, the familiarity between the main actors and the formation of committees were the most significant characteristics [49,50]. In a study performed in India that also employed social network analysis, Ashton and Bain [51] identified a high level of shared standards in the network. Nevertheless, the exchange of by-products exhibited a weak correlation with structure and communication.

In more recent IS analyses, Australian experiences pointed to the support of local and state governments, economic factors, and regulation as crucial components to stimulating or preventing interest in establishing synergistic relationships [52]. In another analysis set in Australia, Golev et al. [53] identified non-technical aspects, cooperation, and trust as the most significant elements for developing synergies in the region. In Finland, Kokoulina et al. [54] realized that little attention had been given to IS issues at the individual level and examined their facilitation process by analyzing the champion's role. In Brazil, research into overcoming social barriers to promote synergies between companies indicated that values such as benevolence and universalism, trust, cognitive mastery over waste, and environmental engagement were fundamental [55]. In general, studies on IS have begun to acknowledge the relevance of social factors such as trust and collaboration in IS implementation $[45,56]$. However, there is still little research into what constitutes trust and collaboration and how they influence decisions $[57,58]$. Other factors, such as organizational difficulties [59], individual motivations and dynamics [34], and government actions [35], are also included in this list of relevant factors. Nonetheless, as Yap and Devlin [60] stated, in most IS analyses, the company level is usually underexamined, and when the context is acknowledged, it is underspecified.

The impact of policy instruments, the mechanisms of policy intervention, and facilitation of IS are not completely clear. However, it is evident that government plays a crucial role in driving firms' initiatives [35,61,62]. Van Berkel et al. [63] analyzed the results and experiences from Japan's key efforts to foster IS and listed the following factors that led to their success: availability of investment subsidies, recycling-oriented legislation, access to technological resources from the private sector, and an urgency to act on environmental issues. In a comparative analysis, Mathews and Tan [64] found that a top-down approach 
ensured by institutional arrangements, such as regulatory requirements, facilitated EIP's evolution in China.

The studies presented herein point to valuable advances in understanding the complexity of the IS phenomenon; however, most analyses are based on studies that look into a single case and focus on different factors in isolation [65]. This diversity of findings and approaches inhibits a more comprehensive formulation of the phenomenon and fragments the field. To provide a better understanding of the dynamics involved in the emergence of the IS process, this systematic comparison of different contexts explores the following fundamental questions: What causes IS to emerge in different countries? To what extent are these causes specific to the country? What conditions are generally more or less favorable? Who are the main actors, and what are their roles in the implementation of IS? Which mechanisms of policy intervention are more effective in supporting the implementation of IS?

\section{Materials and Methods}

Given the need to go in depth and detail the IS implementation process, we applied a qualitative approach [66]. We performed documentary research whose sources of information were initially scientific papers, and we later added websites, research reports, theses, and dissertations.

We selected the cases based on three criteria: accessibility and quality of available data, maturity level of interorganizational relationships, and degree of homogeneity of the cases. To assess the accessibility and quality of the data, we used the comprehensive review developed by Neves et al. [12], which mapped all existing IS cases in the world. From their analysis of the cases, we were able to verify the methods applied in each study. Based on this information, the cases of Kalundborg, Kwinana, and Ulsan became viable as the collected data in reference to these cases included quantitative data on environmental, economic, and social benefits; GHG emissions; and field visits, interviews, and analyses of the IS development process.

With regard to the maturity level of interorganizational relationships, Kalundborg is considered to be the standard model for EIP development in the world. Due to their tremendous integration among managers and their perception of opportunities for collaboration, the Kalundborg EIP industries are known for their "short mental distance" [43]. In terms of the level and maturity of industry involvement and collaboration and commitment to future regional synergy resources, Kwinana is compared to renowned inter-national examples of regional synergy development, such as Kalundborg [67]. The synergies between the companies at Ulsan have evolved continuously since 1990. They have active partnerships, while others are in negotiation and in the design phase, and the feasibility of several partnerships are under investigation, which all demonstrates maturity in interorganizational relationships [68].

We employed the following parameters to determine the homogeneity of the cases: diversity of industries, number of synergies, and initial dynamics of IS development. As for the types of industry, the three cases include manufacturing, energy supply, water and waste, agriculture, sale and repair, construction, and mining and quarrying, thus, constituting diversity in economic activities. With respect to the number of synergies, we chose cases that had a higher level of complexity/relationships among companies. According to Zhu and Ruth [69], Kalundborg EIP has 13 firms and 14 symbiotic pairs, Kwinana has 16 firms and 28 symbiotic pairs, and Ulsan has 11 firms and eight symbiotic pairs. Additionally, Kalundborg and Kwinana have five and nine utility networks, respectively. In relation to the initial dynamics of IS development, which Boons et al. [36] define as the typical pathways through which the IS process unfolds, the Kalundborg and Kwinana EIPs formed through self-organization. In other words, the development of symbiotic activities resulted from the self-motivated strategies of industrial actors. Although Ulsan EIP is not listed as a self-organizing EIP in Boons' classification, Park et al. [68] assert that Ulsan developed spontaneously, incited by economic benefits and regulatory constraints. Therefore, the three EIPs meet this final criterion. 
Once we defined the cases, we conducted three systematic literature reviews (SLRs) in five steps (Table 1), so as to extract the most comprehensive list possible of all the published studies based on explicit, rigorous criteria [70]. According to Chandler et al. [71], a SLR constitutes a review of a clearly formulated question that uses systematic, explicit methods to identify, select, and critically appraise relevant research and to collect and analyze data.

Table 1. The SLR Process.

\begin{tabular}{|c|c|c|}
\hline Protocol Steps & Description & Application \\
\hline $\begin{array}{l}\text { (i) Formulate the } \\
\text { research question }\end{array}$ & $\begin{array}{l}\text { The research question identifies the } \\
\text { problem to be studied and drives } \\
\text { the entire SLR process. }\end{array}$ & $\begin{array}{l}\text { How did the implementation process for the } \\
\text { industrial ecosystems of the industrial parks of } \\
\text { Kalundborg, Denmark; Ulsan, South Korea; and } \\
\text { Kwinana, Australia arise? }\end{array}$ \\
\hline $\begin{array}{l}\text { (ii) Set inclusion or } \\
\text { exclusion criteria }\end{array}$ & $\begin{array}{l}\text { The selection criteria might include } \\
\text { databases, keywords, types of } \\
\text { journals, language, research period. }\end{array}$ & $\begin{array}{l}\text { We collected data from three major databases: } \\
\text { Scopus, Web of Science, and Science Direct. We } \\
\text { selected only scientific papers without defining any } \\
\text { criteria relative to time. As for keywords, we used } \\
\text { combinations that included the terms "industrial } \\
\text { ecology" OR "industrial symbiosis" OR "industrial } \\
\text { ecosystem" and each of the cases "Ulsan," } \\
\text { "Kalundborg," and "Kwinana" and in the titles, } \\
\text { abstracts, and keywords. }\end{array}$ \\
\hline $\begin{array}{l}\text { (iii) Select and access } \\
\text { the literature }\end{array}$ & $\begin{array}{l}\text { At this stage, papers are collected, } \\
\text { and duplicate } \\
\text { documents are eliminated. }\end{array}$ & $\begin{array}{l}\text { After discarding the duplicates, we found the total } \\
\text { number of papers for each case: Kalundborg, 55; } \\
\text { Ulsan, 24; and Kwinana, } 17 .\end{array}$ \\
\hline $\begin{array}{l}\text { (iv) Assess the quality of the } \\
\text { literature included in the review }\end{array}$ & $\begin{array}{l}\text { Each paper's abstract, title, } \\
\text { keywords are evaluated according } \\
\text { to quality criteria. }\end{array}$ & $\begin{array}{l}\text { We analyzed the papers' abstracts to verify their } \\
\text { relevance, alignment, and quality and } \\
\text { kept } 96 \text { papers. }\end{array}$ \\
\hline $\begin{array}{l}\text { (v) Analyze, synthesize, and } \\
\text { disclose findings }\end{array}$ & $\begin{array}{l}\text { After the final selection, the entire } \\
\text { paper is analyzed. Statistical } \\
\text { methods can be used to } \\
\text { report the results. }\end{array}$ & $\begin{array}{c}\text { Finally, we read, analyzed, and synthesized all the } \\
\text { papers in detail according to the categories in } \\
\text { the IAD framework. }\end{array}$ \\
\hline
\end{tabular}

We decided to apply the IAD framework as a diagnostic and data analysis tool to understand this process. According to Hess and Ostrom [72], the IAD can be used to investigate any broad subject wherein people repeatedly interact with rules and norms that dictate their strategic and behavioral decisions.

The IAD assigns categories to all the explanatory factors and relevant variables of a situation and locates them within a fundamental structure of logical relationships, as shown in Figure 1 [38]. We decided to use only the categories, action situations, and contextual factors for analysis as the scope of our study does not involve an evaluation of the results obtained with IS.

The action situation is an abstraction of the decision-making environment wherein a group of actors interact and make agreements that determine results. Biophysical conditions concern physical and human resources, such as location, the abundance of resources, and technology. The rules in use refer to the existing framework of relevant laws, regulations, rules, norms, and understanding. Finally, community attributes encompass all social and cultural contexts, such as governance structures, values, and trust [38,73,74]. 


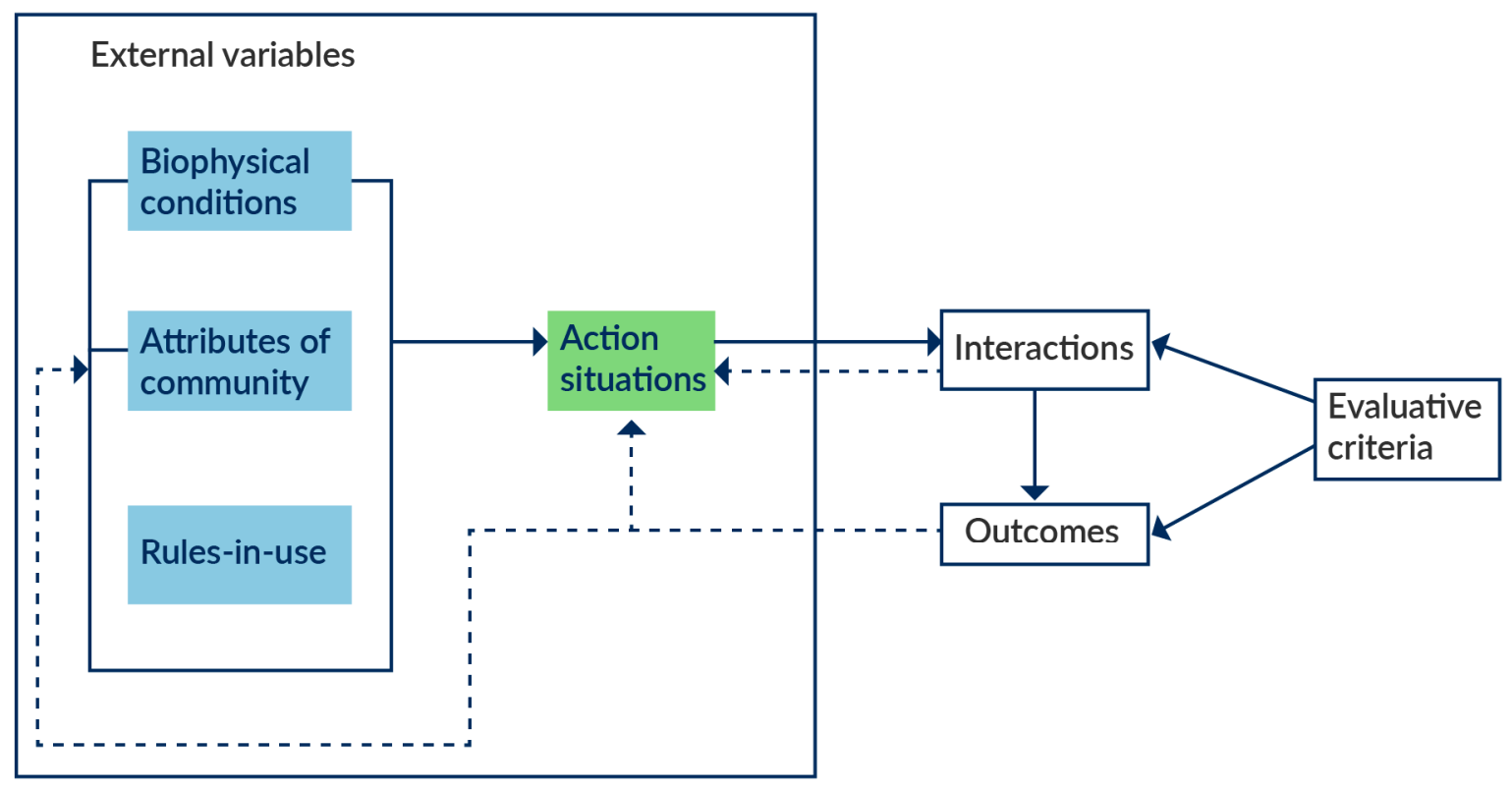

Figure 1. Basic components of the IAD framework. Source: [73]. Reprinted with permission from Elinor Ostrom (2011). 2011 John Wiley and Sons.

\section{Results}

4.1. Kalundborg Industrial District/Denmark

4.1.1. Action Situation

The Kalundborg industrial district was initially formed by four industries, a coal-fired power plant, an oil refinery, a plasterboard factory, and a biotechnology company. The municipality of Kalundborg controlled the city's water, electricity, and the distribution of heating by district [75]. Most of the interactions between the companies involved the flow of steam and purified residual gas [76].

Over time, symbiotic exchanges intensified, and new companies became part of the region's industrial ecosystem. The network now has a power plant, two large chemical companies, a plasterboard factory, a soil remediation company. At the same time, the municipality of Kalundborg acts as a supplier/demander of materials and energy flows, and utilities (Figure 2). Other peripheral actors include farmers in the region, a fishing factory, and some recycling companies that act as receptors of some material flows [77,78].

There are four types of transactions or interactions in Kalundborg's network of symbiotic exchanges: (i) exchange of material waste streams, (ii) exchange and cascading use of water, (iii) cascading use of energy, and (iv) exchange of knowledge. While the first three types denote a tangible component, knowledge exchange refers to an intangible exchange of expertise that can potentially lead to innovation [77].

\subsubsection{Biophysical Conditions}

The region of Kalundborg was once surrounded by rural areas and isolated from large urban centers. In 1959, the first industrial operations began in Kalundborg. From then on, new companies joined the industrial park. Due to the small size of the network of companies, the industrial facilities were closer together, which helped them subvert high transportation costs, reduce transaction costs associated with exchanges, and build trust and commitment among their members $[77,79,80]$.

Annual waste production in the 1970s was already a concern in Denmark. In the city of Kalundborg, located $112 \mathrm{~km}$ from the city of Copenhagen, with a population of approximately twenty thousand inhabitants, initiatives were developed to address this issue. As for the companies, there was interest in managing waste in an environmentally correct and acceptable way through its reuse [81]. 


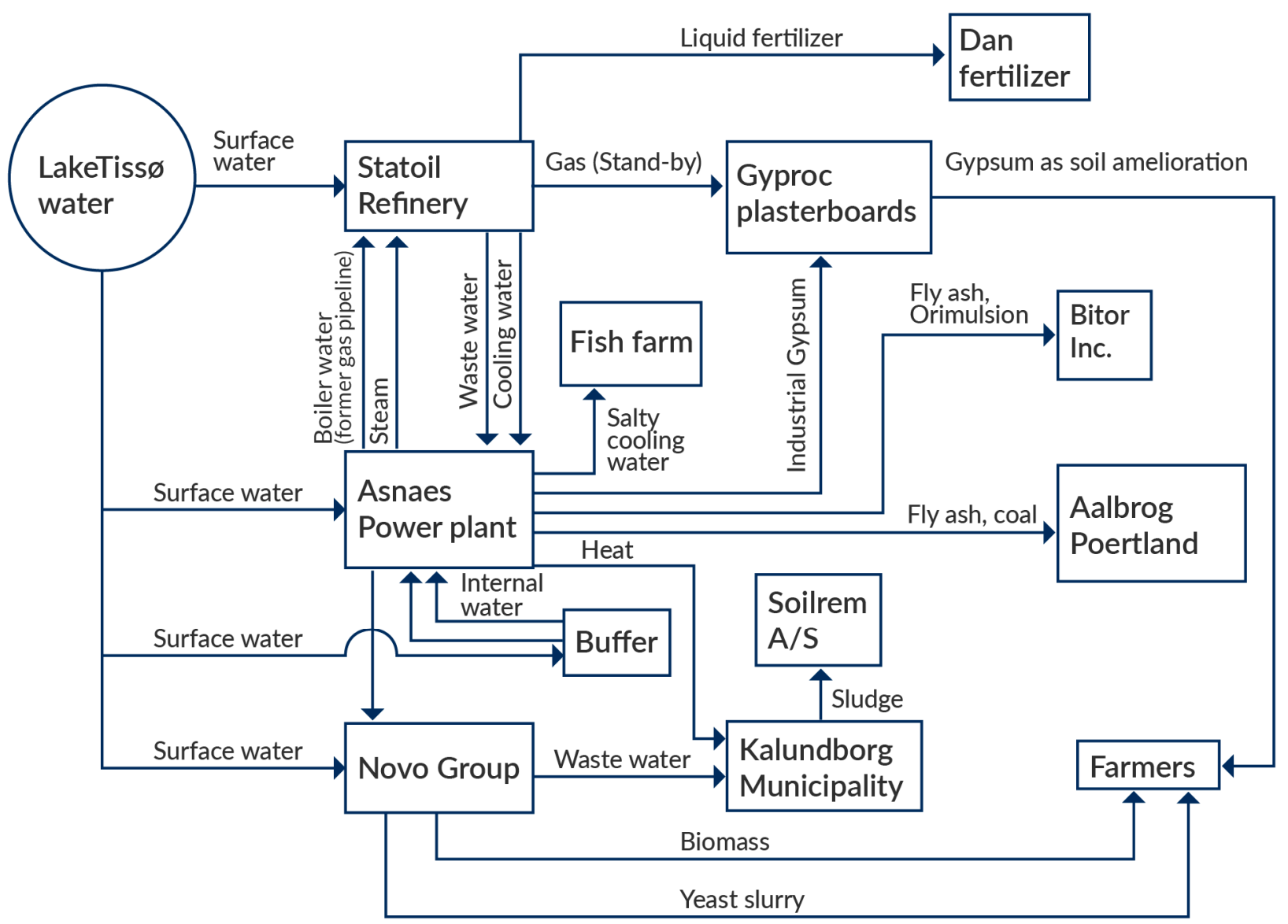

Figure 2. Kalundborg's industrial ecosystem. Source: [78]. Reprinted with permission from Timothy J. Considine (2005). 2008 John Wiley and Sons.

A fundamental variable in the emergence of interactions between companies was the region's large water deficit. The scarcity of fresh water enabled the emergence of new practices related to the use/reuse of water and steam. As local industries expanded in size and consumption, they saw their groundwater supply gradually decline. As a result, there was growing pressure from the actors involved to improve the businesses' environmental performance. Consequently, initiatives by public/private partnerships were designed to mitigate this problem. The main strategies were to replace groundwater with surface water in industries that consume the most, optimize internal water use, improve the quality of drinking water from surface water, and import groundwater from regions adjacent to Kalundborg. This diversified water supply system in the region was made possible by the cooperative relations between the various water-consuming industries and the municipality $[15,43,79,82]$.

The diversity of industries in the region also appears to be a crucial characteristic in the emergence of IS. Kalundborg's leading companies operate in different sectors. The plurality of inputs and outputs of the production processes presents itself as an opportunity to develop symbiotic relationships and promote the system's stability and resilience $[80,82,83]$.

\subsubsection{Community Attributes}

Community attributes influencing the companies to make exchanges included close personal relationships, shared values, and an understanding of the local context $[79,80]$.

Bilateral agreements were primarily driven by economic gains and are seen as the foundation for the initial development of IS in Kalundborg [39,84]. However, we must consider the social aspects of the community's composition in the same age group as the companies' managers, whose children led them to frequent the same social environments, 
such as schools, clubs, and churches. Social interactions in these environments also promoted collaborations between companies. Shared identity is considered an important factor in the success of Kalundborg's IS [33,80]. Although part of the literature on Kalundborg does not mention the champion, in a more recent study, Branson [57] claims that senior managers in participating industries played the role of the champion by establishing various relationships during commercial activities.

Communication and information sharing between the organizations' employees went beyond organizational boundaries. There were frequent meetings between the companies' top management to discuss strategies and projects for implementation. This interaction did not necessarily apply to the organizational level as the executives were members of the same local clubs and informal forums. There was also a somewhat more informal interface at the middle management level. The managers of this hierarchical level participated in a local community club for Sustainable Development (SD). This familiarity generated ideas for synergy projects between industries. This more integral view of the processes promoted collective awareness in the community $[43,80]$.

One of Novo Nordisk's executives referred to this integration between managers and the perception of opportunities for collaboration between industries as "close mental distance." Activities such as training between companies also intensified this integration. In addition, by developing projects together on issues related to the exchange of materials and energy and sharing their problems, the community began to build an environment of trust $[51,79,83,85]$.

Technological and regulatory changes became necessary after the inclusion of these new members and the evolution of the symbiotic relationships. To maintain this collaborative dynamic and facilitate the integration of new members, the Kalundborg Symbiosis Center was founded in 1996. The Center's main function is to collect data related to IS and to distribute project information. In addition to coordinating studies and encouraging cooperation between industries, the Center also receives academics and professionals who want to learn from the Danish experience $[33,78,86,87]$. Nevertheless, to encourage IS on a broader scale, the Symbiosis Center Denmark was created in 2015. The Center's work goes beyond the scope of large companies. They assess the repressed potential of IS in small and medium-sized companies [88]. Figure 3 shows the main actors and their roles in Kalundborg's governance structure.

\subsubsection{Rules in Use}

The changes in the behavior of Kalundborg's industries have had a strong influence on the Danish regulatory framework. Government regulation has restricted emissions of certain materials, such as sulfur dioxide, in the air and sludge to the fjord. Certain practices, such as discharging "thermal pollution" from hot water into fjords, have also been prohibited. These requirements forced some industries to adopt new measures that result in additional costs. However, the government provided subsidies to defray part of the costs $[79,80]$.

Despite this government intervention through command-and-control instruments, the Danish regulatory system called for a voluntary, more proactive approach by companies. Companies usually send their action plans to the government, which detail their initiatives to reduce their environmental impact. This environment, consultation, and collaborative dialogue between government and industry led companies to find creative ways to incorporate more efficient processes that meet the performance criteria set by the government. Many of the creative arrangements were only possible because there was flexibility in meeting the goals $[57,79,80,83]$. By establishing performance standards to the detriment of technology standards, the legislation enabled companies to choose technologies to make their waste streams profitable as raw material in other processes [83]. 


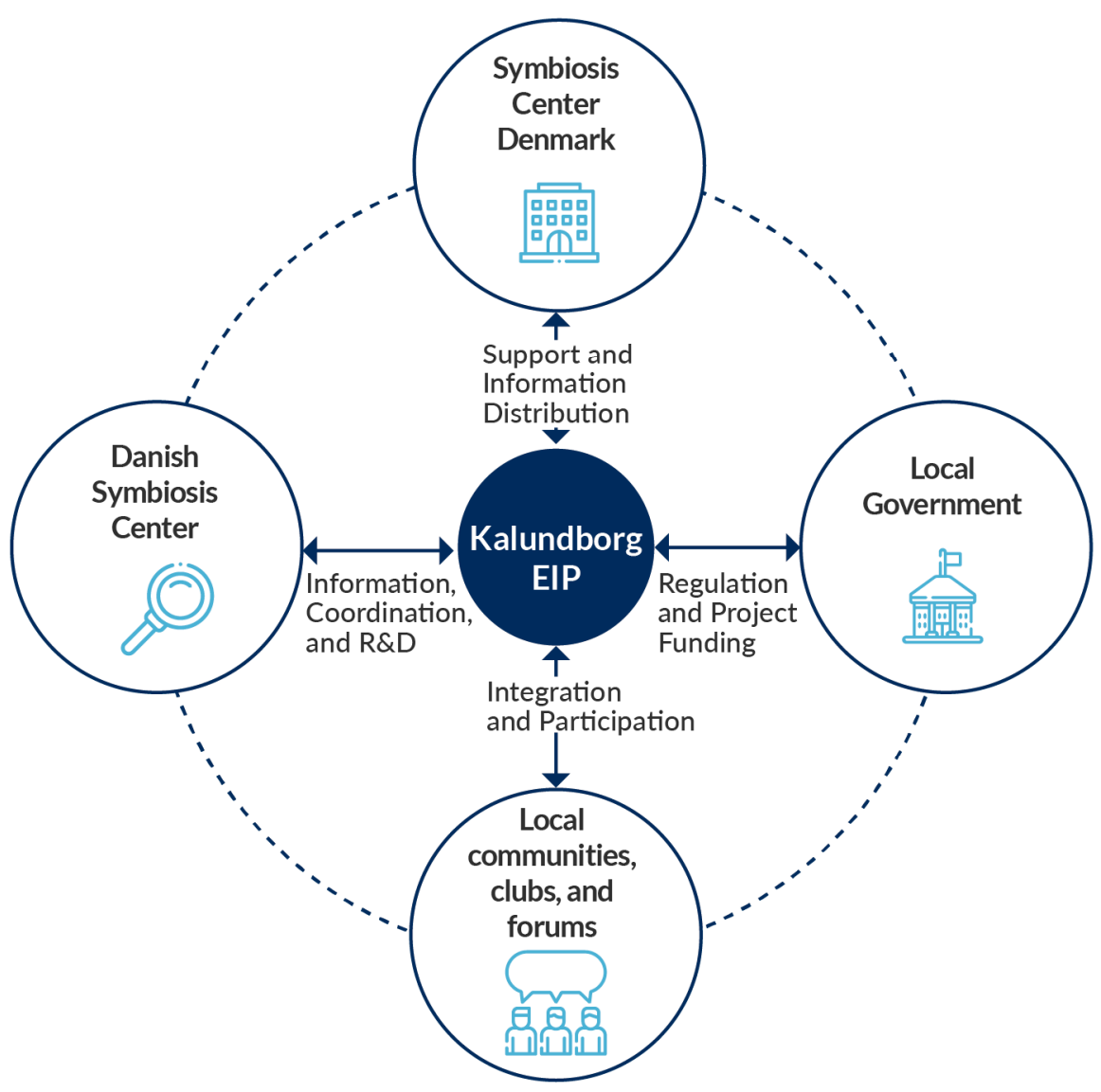

Figure 3. Kalundborg's Governance Structure.

\subsection{Ulsan Industrial District, South Korea}

\subsubsection{Action Situation}

Originally organized as a conventional industrial district, the Ulsan industrial complex was part of South Korea's government plan to encourage the development of heavy industry. This plan aimed to increase Ulsan's population to half a million people and establish the city as a regional center for industry and culture. As a result, there was a strong presence of petrochemical, non-ferrous metal, shipbuilding, and automobile industries [89].

Records from the 1990s point to the spontaneous emergence of symbiotic relationships due to environmental regulation and economic benefits. Partner industries have developed a series of bilateral exchanges involving energy, gas, waste, and water. The companies themselves created collective utility systems for managing electricity, water, and steam needs. The purpose was to meet local demand, that is, a transition from a conventional industrial complex to an industrial ecosystem that evolved from bilateral agreements seeking environmental and economic benefits in each relationship [68,89,90].

Six actors initially formed the structure of Ulsan's action situation: Koentec Ltd., an industrial waste treatment and disposal company; SK Corp., a petrochemical company; SK Chemicals Corp., a leader in the development of high-performance resin; LG-Nikko Corp., a leader in the copper foundry industry; Koreazinc Corp, a manufacturer of non-ferrous metals; and the metropolitan city of Ulsan was responsible for operating the municipal wastewater treatment plants [91].

The number of synergies grew over time. Behera et al. [61] pointed to thirteen symbiotic relationships in Ulsan (Figure 4) involving 41 companies. There is a considerable diversity of interactions in the network. Six of them involve steam exchanges, while the rest are by-product exchanges. 


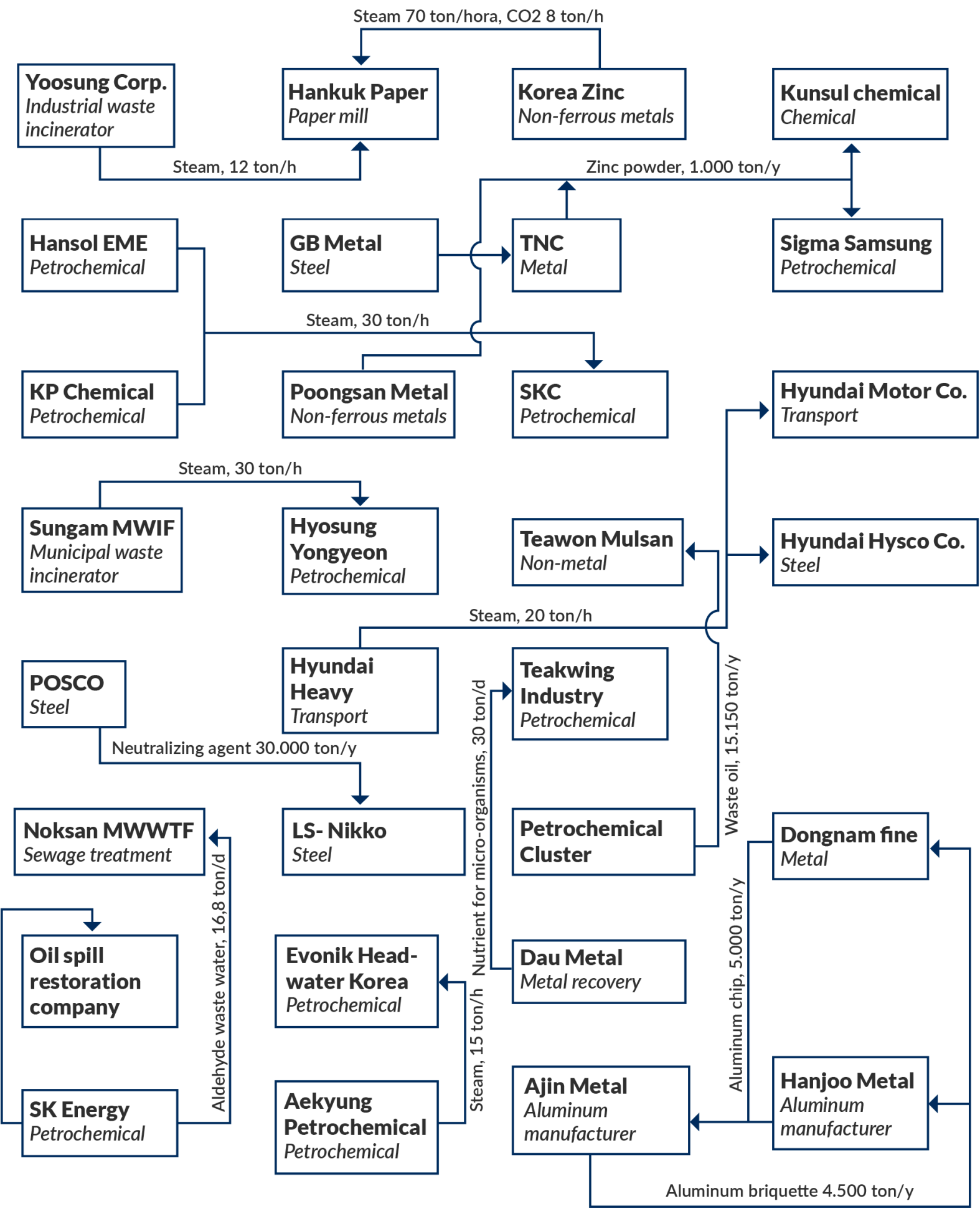

Figure 4. Symbiotic exchanges of the Ulsan industrial ecosystem. Source: [61]. Reprinted with permission from Shishir Kumar Behera, Jung-Hoon Kim, Sang-Yoon Lee, Sangwon Suh, Hung-Suck Park (2012). 2012 Elsevier.

\subsubsection{Biophysical Conditions}

Until about 1960, Ulsan was a small fishing and agricultural village located about $389.5 \mathrm{~km}$ from the southeastern tip of the capital, Seoul. The region had about 85,000 inhabitants whose main activities were agriculture and subsistence fishing. The population was concentrated in small villages. In 1962, Ulsan was granted city status by the government as 
part of a national economic development plan. In the following years, the city became the industrial capital of South Korea with a great diversity of industries [89,92].

This radical economic transition in South Korea that began in 1960 was structured around industrial complexes to promote the development of priority sectors [93]. As was the trend at the time, Ulsan's growth was focused on improving economic performance and establishing large heavy industries. Because of this expansion, pollutants such as sulfur dioxide and nitrogen dioxide were generated at an alarming rate. Aside from air pollution, large amounts of effluents were discharged into rivers [68,89]. Reports of malaise, headaches, and vomiting by students and teachers from schools located near the industrial complex evidenced the government's and industries' inattention to the issue of pollution. As a result, many schools closed or changed their location due to the negative impacts on the students' health $[89,94]$.

Crop damage, discomfort in the population, and river pollution were just some of the negative effects of the region's industrialization process. In addition, many companies have had to compensate those affected by the pollution financially. Given this scenario, the industrial areas and the government faced increasing backlash and popular pressure for the industrial activities' impacts on the environment and human health $[93,95,96]$.

To resolve these issues, the government imposed strict environmental regulations in the 1990s. Therefore, the industries had to adapt to the new legislation by investing in pollution prevention equipment, establishing a system for cleaner production, and developing environmental management plans based on ISO $14001[89,91]$.

Another significant factor in the South Korean context at the time was the strong dependence on foreign resources. Park [89] reports that South Korea imported much of its energy, petrochemical inputs, and industrial commodities. It was the seventh-largest consumer of oil and the fifth-largest importer of liquid oil in the world. In other words, the South Korean economy relied on international resource markets and price fluctuations, which can be affected by several factors, such as natural disasters and regional conflicts. As a result, symbiotic exchanges between industries would reduce this external dependence on resources.

\subsubsection{Community Attributes}

There was already some cooperation based on exchanges between some industries in the Ulsan industrial park in the mid-1990s. Partnerships established through bilateral exchanges involving energy, gas, waste, and water suggest the first approach to collaboration and cooperation by industries. When South Korea set forth a new policy focused on industrial eco-development, the organizations' involvement and cooperation were vital factors to meeting the objectives for SD [90].

Creating a governance structure to facilitate the transition process from conventional industrial complexes to an EIP was fundamental to promoting social familiarity to the common culture and trust that existed among stakeholders. These bonds helped minimize uncertainties and risks $[61,97]$.

In the first two years, the project did not achieve the expected success, mainly because it ignored the companies' needs and interests. The executives' lack of participation required a strategic realignment to encourage a more proactive integration of business actors $[90,93,98]$.

For greater stakeholder engagement, the government established regional EIP centers responsible for mobilizing all the actors involved in the transition process. In addition, business actors, universities, research institutes, and local governments participated in forums to promote communication, information sharing, and cooperation [98].

The main stakeholders (Figure 5) in the Ulsan project were the Ulsan EIP center, the Ulsan Metropolitan City government, research and development (R\&D) centers, and the Korea Industrial Complex Corporation (KICOX). Additionally, local and regional nongovernmental organizations (NGOs) have shown an interest in participating in project development activities $[61,68]$. 


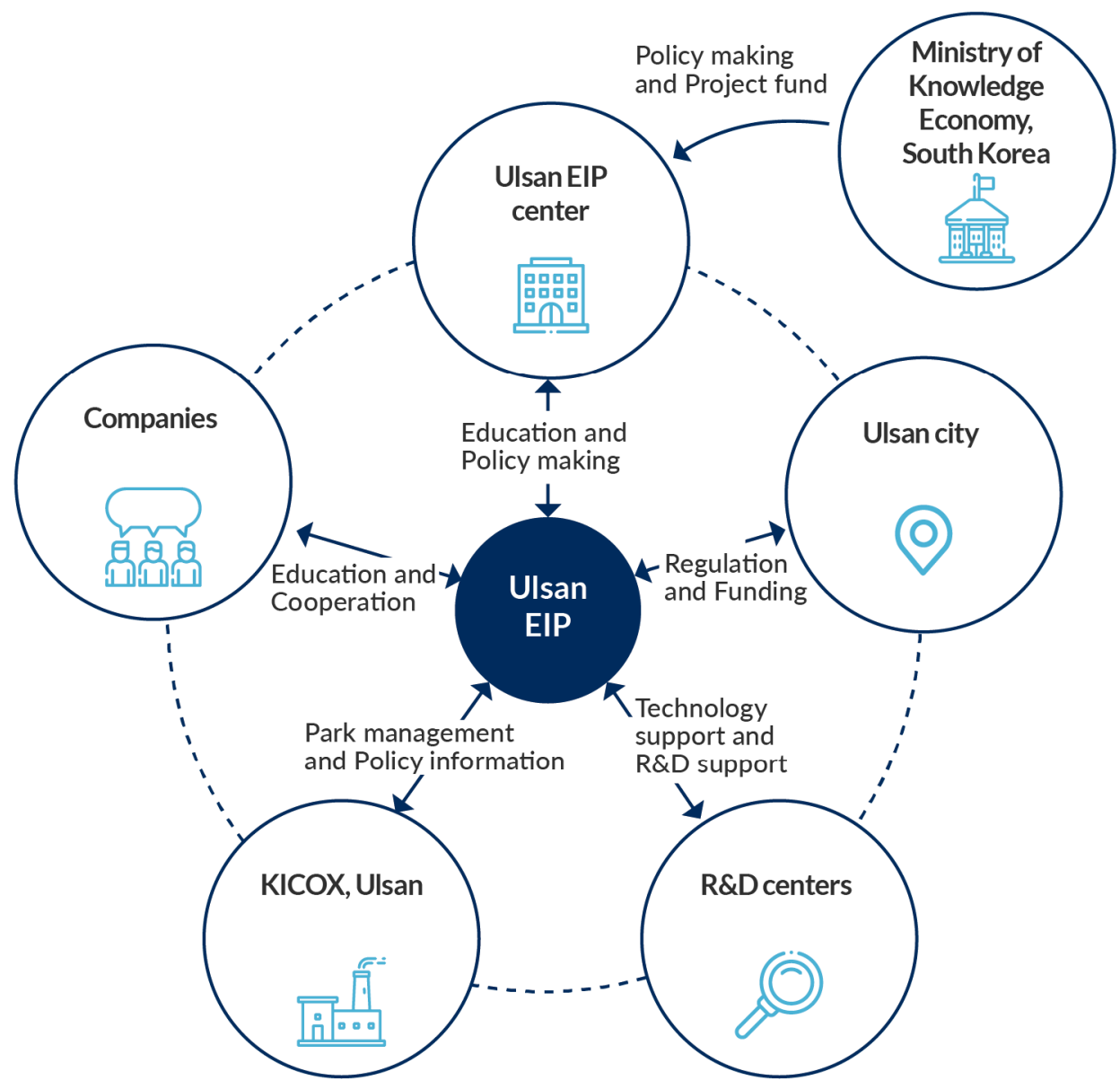

Figure 5. Ulsan's Governance Structure. Source: [61]. Reprinted with permission from Shishir Kumar Behera, Jung-Hoon Kim, Sang-Yoon Lee, Sangwon Suh, Hung-Suck Park (2012). 2012 Elsevier.

Tied to the structure of regional centers is the champion, academic member, or manager of any of the companies who knew the local community and the existing culture. These closer relations between the actors were essential to promoting social connections and developing trust in the EIP development networks [93,99].

\subsubsection{Rules in Use}

When the expansion of Ulsan's conventional industrial complex began, there was little emphasis on the environment. The development of heavy industry and petrochemical plants created terrible environmental conditions. High emission rates of greenhouse gases and large amounts of pollutants dumped into rivers gave Ulsan its reputation as the most polluted city in the country. Since then, legislation has become stricter with emissions and environmental safety in the region. In addition, waste treatment has posed a major challenge to companies $[89,93,100]$.

At the national level, the South Korean government made advances related to environmental issues. However, the substantial change came after the United Nations Conference on Environment and Development in 1992. New legislation redefined the foundations for environmental industrial policy and was quickly developed with the participation of citizens and the commitment of local governments. Many local governments had an active role in establishing Agenda 21. As a result, environmental policy transitioned from reactive and passive to proactive and cooperative [68,96,97].

In 1995, the Ministry of Commerce, Industry, and Energy enacted a law to promote the green industrial structure. Based on this law, planned initiatives included transferring and disseminating cleaner production practices through the transfer of technology and 
promoting the environmental industry and an environmental management system based on ISO $14001[91,97]$.

In this context of changes at the regulatory and institutional level, the National EIP Program emerged as an alternative to the conventional industrial park model. The National Center for Cleaner Production in Korea (KNCPC) and the Korean Institute of Industrial Technology (KITECH) are the main national actors in the program's implementation and strategic supervision. In addition, the South Korean government has provided economic incentives for research and studies on the feasibility of attracting private investments to the program and encouraging business participation [68,98].

At the local level, the municipality of Ulsan initiated the Ulsan EcoPolis program in 2004, whose principle is the harmonious coexistence between industries, the environment, and human beings. Local government support for SD provided conditions for the industrial transition. In 2005, the Ulsan industrial complex was chosen as one of the pilot projects for the national EIP program [90].

\subsection{Kwinana Industrial District, Australia}

\subsubsection{Action Situation}

The Kwinana industrial park (KIA) includes many industries, from manufacturing and construction facilities to high-tech chemical and biotechnology plants. It also has large resource processing industries, such as titanium dioxide pigment; pig iron; cement; and alumina, nickel, and oil refining. These industries are substantially integrated and connected. Several companies produce raw materials essential to the manufacturing and refining processes of other nearby companies [101,102].

KIA has a diverse range of mineral processing industries and other heavy industries: an alumina refinery (Alcoa), a nickel refinery (Kwinana nickel refinery), a titanium dioxide pigment plant (Tiwest), a lime and cement kiln (Cockburn Cement), an oil refinery (BP), and a pig iron plant (HIsmelt). In addition, a variety of chemical producers complement these industries: CSBP (ammonia, ammonium nitrate, cyanide, chlor-alkali, and fertilizers), Coogee Chemicals (inorganic chemical products), Nufarm (herbicides and other agricultural products), Nufarm Coogee (chlor-alkali), Bayer (agricultural chemical products), Chemeq (veterinary products), Ciba (chemical processing), and Nalco (water treatment). There are also important public utility operations: two power plants, two cogeneration plants, two air separation plants, a grain handling and export terminal, a port authority, and a water and sewage treatment plant $[52,103]$.

The existing synergies evolved in response to perceived business opportunities and considerations relative to the environment and resource efficiency. The benefits were not only commercial, but they were also strategic, as the synergies meant less exposure to risk and, frequently, an improvement in the organizations' reputation [102].

The number of interactions has increased considerably since the 1990s. For example, an inventory made in 2005 revealed 47 synergy projects in operation, 32 of which related to exchanges of material waste streams, while 15 related to energy and water exchanges, as shown in Figure 6 [104,105].

\subsubsection{Biophysical Conditions}

The KIA is located in Western Australia, $40 \mathrm{~km}$ south of the capital, Perth, on the shores of Cockburn Sound, a sensitive marine environment with a deep-water port. The park was established in the 1950s, following an Australian parliament law that guaranteed an area of approximately 120 square kilometers to accommodate the development of the main resource processing industries in Western Australia, which triggered the emergence of the region's first large industrial complex $[103,106,107]$.

Given the large concentration of industries in the region, air quality became a topic of discussion between the community and industries due to the rise in pollution levels. Moreover, the park's location on the margins of a sensitive marine environment and near 
urban areas led to growing community pressure on industrial operations' performance and environmental safety $[105,107-110]$.

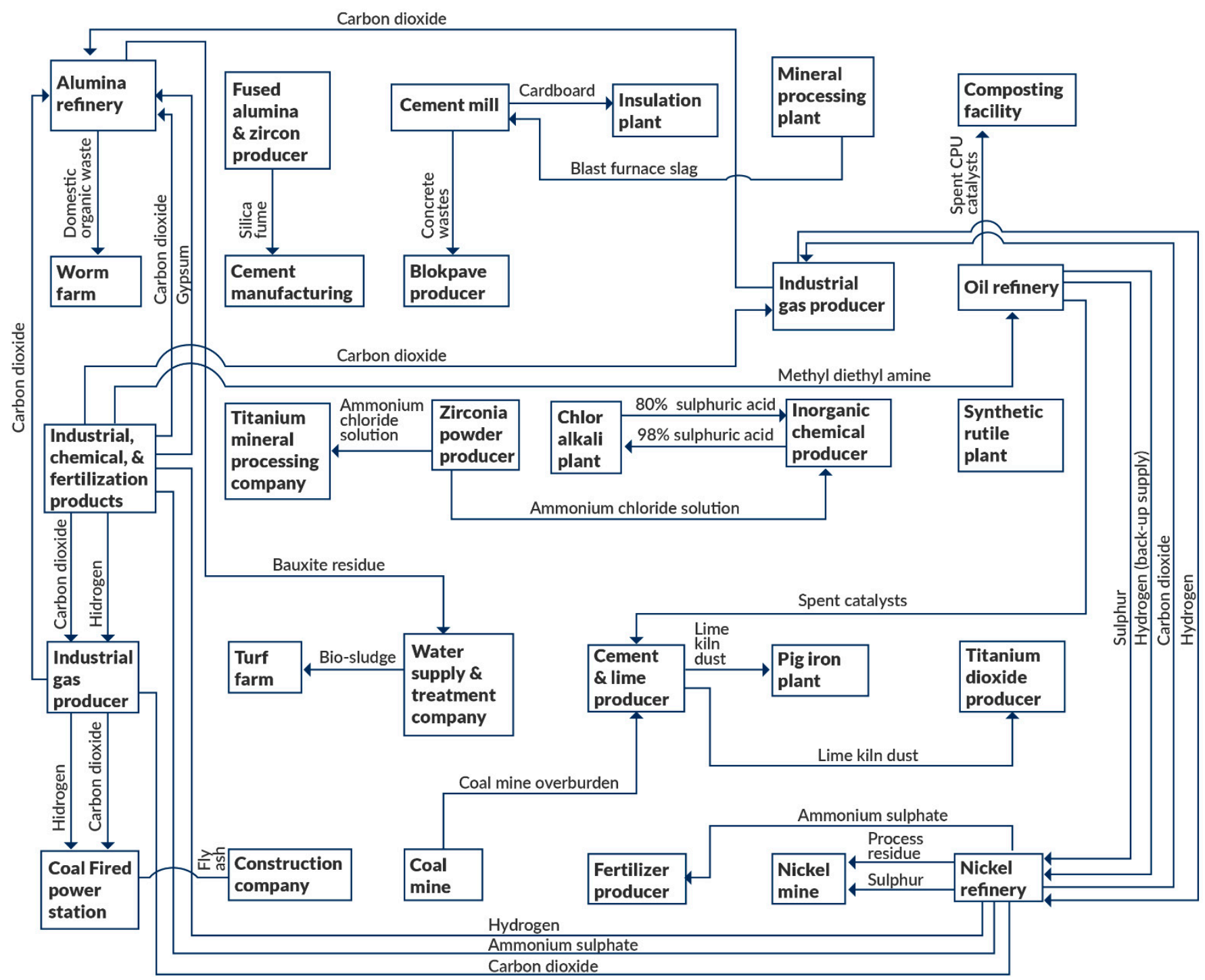

Figure 6. Symbiotic exchanges of the Kwinana industrial ecosystem. Source: [67]. Reprinted with permission from Rene Berkel, Glen Corder, Albena Bossilkov, et al. (2007). 2008 John Wiley and Sons.

The scarcity of resources was a crucial factor in sparking interactions between the KIA industries. Due to the decline in groundwater and water levels stored in dams, fresh water would be a scarce resource for the following decades, and the cost of water would have likely increased over time as a result. Thus, several synergies were developed due to concerns over continued access to this vital resource by various businesses. A water reclamation plant was built to accommodate this demand [102,103].

Another component that facilitated the KIA industries' adoption of new practices was the technical obsolescence of existing equipment. As their machinery aged and needed to be replaced, companies saw new technologies as an economically viable option [105]. Other factors also contributed to the industrial park's evolution towards IS: the geographical distance from other industrial parks; the diversification of the processing and manufacturing industries that produced mainly for international markets, with little local competition between industries in the area; and a large amount of waste in the mining supply chain [111]. 


\subsubsection{Community Attributes}

There was already considerable integration of the supply chain in heavy industry and mineral processing production processes. Several companies produced raw materials essential to the manufacturing and refining processes of this type of industry. At the KIA, these relationships went beyond simple integration of the supply chain and moved towards symbiotic relationships [103].

The first symbiotic exchanges in the park occurred in the late 1980s through bilateral exchanges. However, at that time, there was no formal organization by the Kwinana industries that could systematize these exchanges, distribute information, or promote these relationships. Over time, demands related to monitoring air and water quality intensified not only for industries but there was also growing pressure from the community and local government. As a result, the Kwinana Industrial Council (KIC) was created in 1991 to meet these demands. Its immediate objective was to organize water and air issues collectively. In addition, the establishment of this organization facilitated formal and informal communication between members [102,112].

The consolidation of the KIC as a representative and deliberative entity made it possible to appreciate and develop new initiatives. Its scope of action was expanded to meet new requirements. KIC established broader and more effective communication by forming committees that had monthly or bi-monthly meetings. In addition to the participating companies, this communication strategy included other actors either directly or indirectly involved with the park. Fostering and fortifying relationships are fundamental components of IS. These relationships generate a greater level of cooperation and trust in the community and, as a consequence, contribute to the development of new opportunities for synergy and other joint initiatives $[103,110]$.

Van Beers et al. [105] add that the mobility of technical staff between industrial operations also contributed to the emergence of symbiotic exchanges. There were two forms of mobility. First, mobility occurred across similar sectors through information sharing by industries in the same sector located in different industrial parks. This exchange of knowledge allowed for better efficiency and operational performance. Second, mobility occurred across different industries, enabling the technical staff of different companies to better understand the inputs and outputs of other industrial processes, which helped identify opportunities for synergy.

All the collaboration and participation to handle the various problems faced by the industries and the community allowed the number of symbiotic exchanges and groups to increase substantially. The distribution of information and transparency also improved through publications on the Council's website. As a result, the participation of community members and groups became recurrent. This collective engagement demonstrated all the actors' commitment to improving local sustainability through the peaceful coexistence of industry, local government, and the community $[110,113,114]$.

Building and consolidating IS relied on the involvement of several actors (Figure 7): the Cooperative Research Center for Sustainable Processing of Resources (CSRP) and the Australian universities that support several types of research in Kwinana; the Western Australia Sustainable Industries Group, a government- and industry-funded association that advocates a sustainable approach to business; the Western Australian Chamber of Commerce and Industry; the KIC; and local government [103,110].

\subsubsection{Rules in Use}

Initially, the conditions that led to the emergence of synergies between Kwinana's industries were primarily economic. However, due to the community's growing expectations for sustainability and concerns about resource availability, other issues arose. As a result, throughout the 1980s and 1990s, mining and mineral processing companies shifted from an adaptive, resistant stance towards environmental standards to a more proactive stance towards environmental compliance $[105,106]$. 


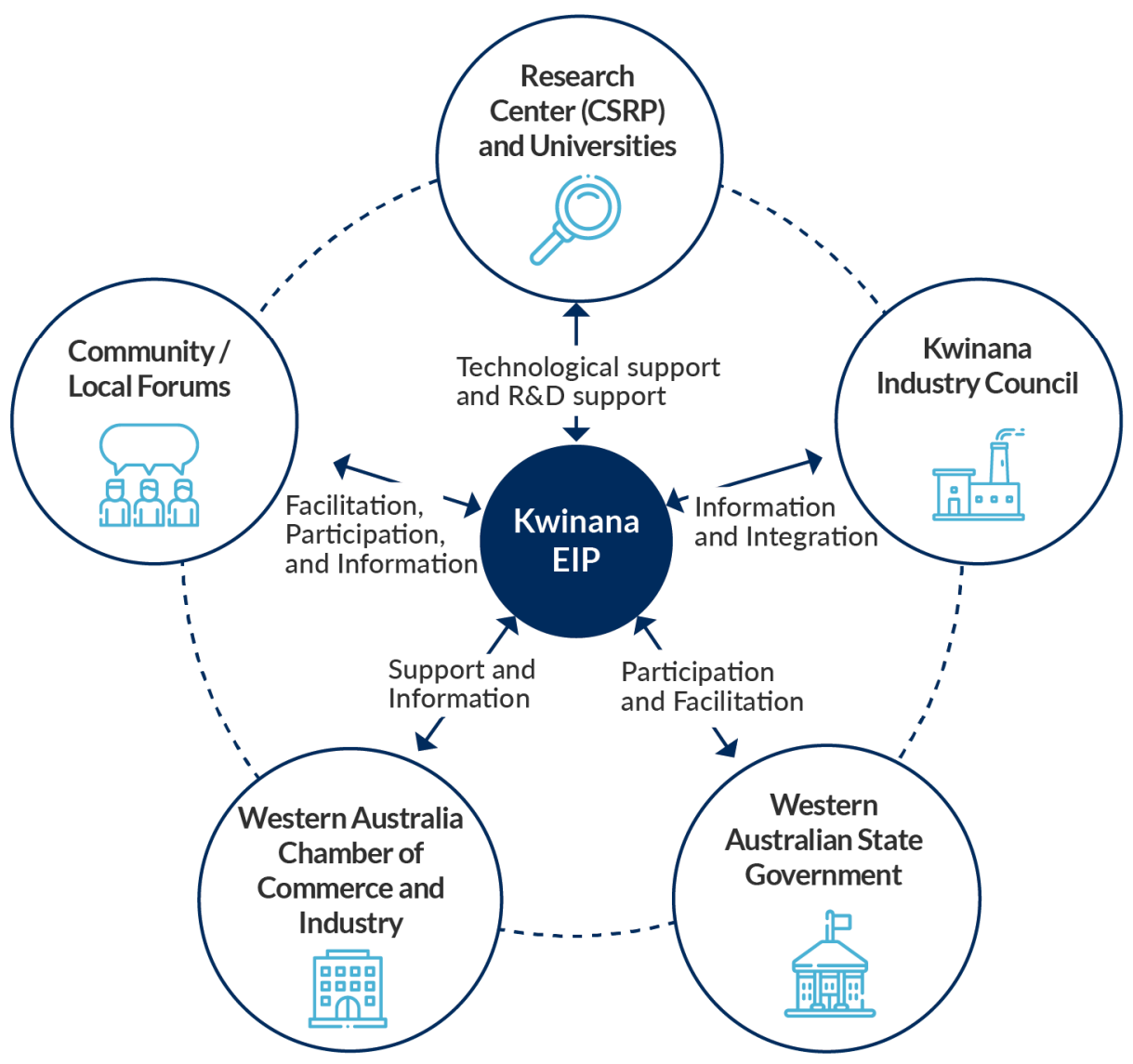

Figure 7. Kwinana's Governance Structure. Source: Adapted from [110].

The Australian federation comprises six state governments, two territorial governments, and one federal government. Each state and territorial government approves the environmental legislation concerning its jurisdiction. Therefore, the federal government has no environmental jurisdiction over states or territories [57].

Although the Australian government had a misaligned position with the objectives of SD, Australian state governments, especially in Western Australia, did not endorse that position. The Western Australia State Sustainability Strategy for the Future was developed between 2001 and 2003, which included 42 sustainability topics that gave rise to over 336 strategies and actions, including sustainability action plans for all government agencies $[108,115]$.

Despite the park's efforts to implement more sustainable practices through synergies, government support at the national level was still inexpressive for some policies. There was a belief that by-products were contaminated, so they had no value to the production process. The regulatory framework prioritized the established raw materials industries instead of allowing the reuse of by-products in different industry sectors. On the other hand, there were regulatory developments related to energy efficiency and energy recovery in response to climate change challenges $[103,104]$.

At the local level, regulation was an important factor in establishing relations between the industries and the community in the Kwinana region. Industries have acted more proactively to resolve issues arising from the local community in anticipation of the requirements for possible regulation. The cooperative environment established between the industry and community reflects progress [110].

\section{Discussion}

To understand the complexity of the dynamics of the IS implementation process and its formation in the three chosen cases, we need to look more deeply and investigate the 
particular context of the organizations. This study used the IAD framework to organize and categorize data on the key contextual factors that interacted to shape the organizations behavioral patterns towards IS. The results of our comparative analysis of the three cases show that although there was no clear, linear order in which the actors developed symbiotic relationships, the decisions related to IS were shaped by a similar set of variables. Based on the convergences found in the three cases, we propose a theoretical and analytical framework (Figure 8).

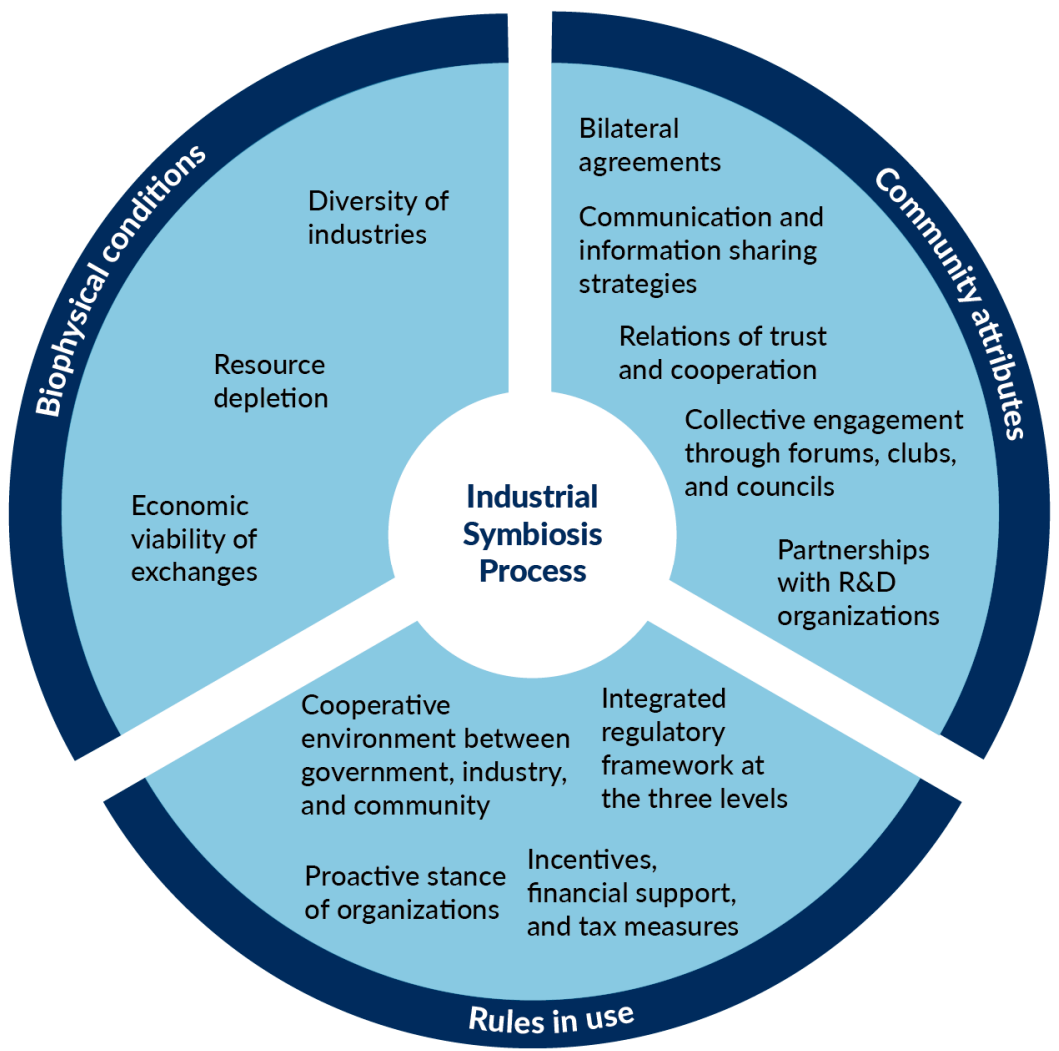

Figure 8. Theoretical and analytical framework for the IS process.

The first set of contextual elements refers to biophysical conditions. These factors reinforce the idea that the organizations' structural evolution is based on entering into any arrangements that minimize transaction costs [116]. Therefore, forming an industrial park presents an advantage to the participating organizations since symbiotic exchanges are more likely to occur in an industrial park with several industries. However, these arrangements will only be made if the exchanges are financially viable, as in an increase in revenue from the sale of by-products and decreased costs by opting for secondary resources. Other variables are also part of this category of the IAD framework, such as available resources, infrastructure, and technology [74]. Specifically for the IS implementation process, it is clear that the lack of resources and environmental degradation resulting from industrial activities are relevant variables since they provoked changes in practices and technologies. Implementing new technologies and practices, such as sharing services and optimizing local resources through the cascading use of water and steam, led to more energy security, better efficiency of the processes, less external dependence on resources, lower costs, and better industry reputation.

However, the biophysical characteristics of the system alone do not adequately explain the IS process. The second set of elements, rules in use, includes laws, regulations, and standards, and it was also a decisive factor of change in the organizations' behavior. As Jiao and Boons [35] state, it is critical to understand how regulatory mechanisms and policy instruments shape local IS practices. Based on our analysis of the cases, we perceived that 
the government played a decisive role in the IS implementation process, either through subsidies, tax incentives, and other measures. Nonetheless, for these policies to be effective, policymakers need a very sophisticated understanding of the processes already underway to establish a regulatory framework consistent with sustainable industrial development [27]. This interaction is only possible when there is a cooperative environment between the government, industries, and the community. In addition to the cases presented herein, we can provide the example of NISP to demonstrate the relevance of government support. Ever since the government ceased funding, the program has struggled to move forward, which indicates that government support is needed if these initiatives are to be successful [117].

The results of the comparative analysis also show that the environmental policies of the 1970s and 1980s, aimed at regulating polluting activities, were undergoing improvements, and new instruments became popular as of the 1990s. A cooperative environment was then forged, which persuaded companies to change through agreements based on understandings between the parties (regulatory agent and company or business group), certifications, and voluntary programs. At the same time, the government defined performance criteria instead of the proper technology. Finally, it became clear that policies must be integrated at national, regional, and local levels. This integrated regulatory apparatus was fundamental to the success of the Kalundborg and Ulsan initiatives. In Kwinana, this integration occurred on a regional basis due to the particularities of the Australian context.

To fully understand the IS process, we must consider the third set of factors, community attributes, which refer to the individuals' social ties and cultural context. Anchored in the concept of social embeddedness, Baas [4] and Boons and Howard-Grenville [7] argue that industrial systems are not automatically organized to close their cycles. In other words, every economic decision is situated in the context of social relations. Therefore, the actions of individuals and organizations that transact material and energy flows can only be understood if they consider the social context in which they operate.

Accordingly, our analysis of the community attributes reveals that the formation of IS starts with bilateral agreements. The three cases demonstrated that bilateral agreements for energy cogeneration, cascading use of resources, and shared services are recurrent practices with local economic and environmental advantages. These bilateral relations found in the modus operandi of the industrial parks functioned as precursors to IS as they promoted this first interaction between the actors. Another common variable across the three cases that helped build social bonds of trust and cooperation was the information accessed and shared by community members through clubs, councils, or forums. Learning generated and shared by the community contributed to the system's capacity for transformation.

Ultimately, from our comparison of the governance structures in each case, we sought to verify the main actors and their roles in the implementation of IS. At this particular point, it is worth to note that the structure established in Ulsan differs from the others in that there is a policy at the national level that encourages and promotes IE [61]. Nevertheless, we observed a governance structure common to all three cases: the local government, the community, companies, R\&D institutions, and a coordinating entity or the champion. This structure is fundamental to fomenting and fortifying relationships as it promotes collective engagement, generates cohesion, and institutionalizes the IS process.

Similar to Ostrom's proposal [118] with the Principles of Design for managing commonpool resources, this study also introduces a set of principles observed in the IS process based on the theoretical and analytical framework presented:

1. There must be a diversity of industries in the region.

2. Exchanges of by-products must be economically viable.

3. Environmental issues such as water scarcity and pollution drive the adoption of IS practices.

4. Initial exchanges are based on bilateral agreements over energy cogeneration, cascading use of resources, and shared services.

5. Stakeholder engagement occurs in forums, clubs, councils, and associations. 
6. The level of trust in relationships corresponds to the level of cooperation between companies.

7. Communication and information sharing strategies reinforce relationships of trust and cooperation.

8. The regulatory framework must be consistent with policies for sustainable industrial development and integrated at national, regional, and local levels.

9. The government and companies' actions must be congruent to create a cooperative environment.

10. The ideal governance structure should involve local government, companies, R\&D institutions, and a coordinating entity or champion.

In sum, the theoretical and analytical framework proposed herein fulfilled its purpose to support a structured reflection on the progress of IS in Kalundborg, Ulsan, and Kwinana. We identified the relevant elements and analyzed each one individually. Al-together, these elements can be translated into policies and actions that can support the current model's transition from a linear production to a circular one. From this perspective, our results suggest some policy and practical implications that could promote the IS projects.

Firstly, our study indicates that policymakers should develop an institutional framework to integrate principles of sustainability into policy-making aligned with ap-propriate market incentives and regulatory instruments at both the local and regional/global levels. For example, policymakers should provide fiscal incentives to reduce the amount of waste streams, to recover more value from them, and to find alternative means for their treatment [41]. They should prioritize the reuse of by-products instead of raw materials [119] and develop quality standards for recycling, life-cycle approaches to waste management and material and energy efficiency, and assessments of the products' environmental performance throughout their whole life cycle [120].

Secondly, our study demonstrates the relevance of collaborative relationships between firms, government, and civil society. The interactive process described in the three cases fostered social learning and innovation. Moreover, a greater involvement of the stakeholders can reduce the level of uncertainty and information asymmetry. Therefore, investing in a participatory governance structure based on knowledge dissemination, public participation, and spaces for dialogue becomes essential to the success of IS initiatives.

Thirdly, our results provide evidence that companies can benefit from proactive measures by adopting standards, improving their products' environmental footprint, sharing infrastructures, and exchanging by-products [62]. In addition to the environmental benefits, all these strategies could provide a substantial competitive advantage for the companies in an era of intense ecological awareness on a global scale.

\section{Conclusions}

This study relied on a SLR in order to extract the most comprehensive list possible of all the published studies based on explicit, rigorous criteria for IS and the three selected cases. We also employed the IAD framework and its categories as a diagnostic and data analysis tool to gather information on the contextual aspects of the social, cultural, institutional, and physical environment that were part of the IS implementation process in the cases of Kalundborg, Ulsan, and Kwinana. Our approach to breaking down the IS process into different components, action situations, biophysical conditions, rules in use, and community attributes proved to be a suitable tool in guiding our analysis of IS development. Its structure helped dismember the complexity of the phenomena into manageable sets of practical activities. It is also useful for comparisons since it contains a universal set of building blocks.

The scope of the study was limited to a partial analysis of the IAD framework as it delved only into contextual variables and action situations. We did not identify the additional elements of the IAD framework, such as interactions, results and their evaluation criteria, and feedback. Thus, we recommend the framework's full application in future 
studies. In addition to documentary analyses, further investigations should conduct interviews with key stakeholders in order to understand their perception of the IS process.

Although we found differences across the cases, the decision over which practices to adopt was based on similar elements, resulting in the proposed framework. The fundamental elements included the diversity of industries; the economic viability of exchanges; critical environmental issues as drivers of more sustainable practices; bilateral agreements as precursors to IS; collective engagement through forums, clubs, councils, and associations; trust to establish cooperative relationships; communication and information sharing strategies; a regulatory framework aligned at national, regional, and local levels; congruence between government and company actions to create a cooperative environment; and a governance structure that involves the local government, companies, R\&D institutions, and a coordinating entity or the champion.

Although these elements have empirical support, it is important to note that they do not necessarily need to be present for IS to occur. According to the results of this study, we may assume that as each principle is met, the chances of success in the IS implementation process increase.

Therefore, this theoretical and analytical framework based on similarities observed in the three cases can serve as a baseline to analyze other initiatives. It can also serve as a reference for diagnostic analyses of aspects for improving IS processes already underway. Moreover, in prescriptive analyses intended to evaluate the potential for implementing IS in a given context, this framework may be useful for policymakers and practitioners to identify the critical elements they need to improve.

Author Contributions: The individual contribution of each author has been as follows: E.F. writing, methodology, formal analysis. A.C.-P. formal analysis and supervision. C.B. methodology supervision and writing-review. All authors have read and agreed to the published version of the manuscript.

Funding: This research received funding from the University of Brasília (DPI)—Process number 23106.065180/2021-25.

Institutional Review Board Statement: Not applicable.

Informed Consent Statement: Not applicable.

Data Availability Statement: The data used in this paper were obtained from a systematic literature review.

Acknowledgments: The authors are grateful to the University of Brasília (DPI) for their support. We are very grateful for the comments and suggestions offered by the three anonymous reviewers.

Conflicts of Interest: The authors declare no conflict of interest.

\section{References}

1. Colby, M.E. Environmental Management in Development: The Evolution of Paradigms. Ecol. Econ. 1991, 3, 193-213. [CrossRef]

2. D'Amato, D.; Droste, N.; Allen, B.; Kettunen, M.; Lähtinen, K.; Korhonen, J.; Leskinen, P.; Matthies, B.D.; Toppinen, A. Green, Circular, Bio Economy: A Comparative Analysis of Sustainability Avenues. J. Clean. Prod. 2017, 168, 716-734. [CrossRef]

3. Saavedra, Y.M.B.B.; Iritani, D.R.; Pavan, A.L.R.R.; Ometto, A.R. Theoretical Contribution of Industrial Ecology to Circular Economy. J. Clean. Prod. 2018, 170, 1514-1522. [CrossRef]

4. Baas, L. Industrial Symbiosis in the Rotterdam Harbour and Industry Complex: Reflections on the Interconnection of the Techno-Sphere with the Social System. Bus. Strateg. Environ. 2008, 17, 330-340. [CrossRef]

5. Bursztyn, M.; Bursztyn, M.A. Fundamentos de Política e Gestão Ambiental; Garamond: Rio de Janeiro, Brazil, 2012.

6. Wallner, H.P. Towards Sustainable Development of Industry: Networking, Complexity and Eco-Clusters. J. Clean. Prod. 1999, 7, 49-58. [CrossRef]

7. Boons, F.A.; Howard-Grenville, J. Introducing the Social Embeddedness of Industrial Ecology. In The Social Embeddedness of Industrial Ecology; Boons, F.A., Howard-Grenville, J., Eds.; Edward Elgar Publishing Ltd.: Cheltenham, UK; Northampton, MA, USA, 2009; pp. 3-27.

8. Ayres, R.U.; Ayres, L.W. A Handbook of Industrial Ecology; Edward Elgar Publishing Ltd.: Cheltenham, UK; Northampton, MA, USA, 2002. [CrossRef]

9. Chertow, M.R. INDUSTRIAL SYMBIOSIS: Literature and Taxonomy. Annu. Rev. Energy Environ. 2000, 25, 313-337. [CrossRef] 
10. Erkman, S. Industrial Ecology: An Historical View. J. Clean. Prod. 1997, 5, 1-10. [CrossRef]

11. Frosch, R.A.; Gallopoulos, N.E. Strategies for Manufacturing. Sci. Am. 1989, 144-152. [CrossRef]

12. Neves, A.; Godina, R.; Azevedo, S.G.; Matias, J.C.O.O. A Comprehensive Review of Industrial Symbiosis. J. Clean. Prod. 2020, 247, 119113. [CrossRef]

13. Bain, A.; Shenoy, M.; Ashton, W.S.; Chertow, M.R. Industrial Symbiosis and Waste Recovery in an Indian Industrial Area. Resour. Conserv. Recycl. 2010, 54, 1278-1287. [CrossRef]

14. Chertow, M.R.; Lombardi, D.R. Quantifying Economic and Environmental Benefits of Co-Located Firms. Environ. Sci. Technol. 2005, 39, 6535-6541. [CrossRef]

15. Jacobsen, N.B. Industrial Symbiosis in Kalundborg, Denmark-A Quantitative Assessment of Economic and Environmental Aspects. J. Ind. Ecol. 2006, 10, 239-255. [CrossRef]

16. van Berkel, R. Comparability of Industrial Symbioses. J. Ind. Ecol. 2009, 13. [CrossRef]

17. European Commission. Cooperation Fostering Industrial Symbiosis: Market. Potential, Good Practice and Policy Actions; European Union: Brussels, Belgium, 2018.

18. Laybourn, P.; Morrissey, M. National Industrial Symbiosis Programme The Pathway To A Low Carbon Sustainable Economy; International Synergies Ltd.: Birmingham, UK, 2009.

19. Branca, T.A.; Colla, V.; Algermissen, D.; Granbom, H.; Martini, U.; Morillon, A.; Pietruck, R.; Rosendahl, S. Reuse and Recycling of By-Products in the Steel Sector: Recent Achievements Paving the Way to Circular Economy and Industrial Symbiosis in Europe. Metals 2020, 10, 345. [CrossRef]

20. Zhang, H.; Dong, L.; Li, H.; Fujita, T.; Ohnishi, S.; Tang, Q. Analysis of Low-Carbon Industrial Symbiosis Technology for Carbon Mitigation in a Chinese Iron/Steel Industrial Park: A Case Study with Carbon Flow Analysis. Energy Policy 2013, 61, 1400-1411. [CrossRef]

21. Yu, B.; Li, X.; Shi, L.; Qian, Y. Quantifying $\mathrm{CO}_{2}$ emission Reduction from Industrial Symbiosis in Integrated Steel Mills in China. J. Clean. Prod. 2015, 103, 801-810. [CrossRef]

22. Ammenberg, J.; Baas, L.; Eklund, M.; Feiz, R.; Helgstrand, A.; Marshall, R. Improving the $\mathrm{CO}_{2}$ Performance of Cement, Part III: The Relevance of Industrial Symbiosis and How to Measure Its Impact. J. Clean. Prod. 2015, 98, 145-155. [CrossRef]

23. Hashimoto, S.; Fujita, T.; Geng, Y.; Nagasawa, E. Realizing $\mathrm{CO}_{2}$ Emission Reduction through Industrial Symbiosis: A Cement Production Case Study for Kawasaki. Resour. Conserv. Recycl. 2010, 54, 704-710. [CrossRef]

24. Marconi, M.; Gregori, F.; Germani, M.; Papetti, A.; Favi, C. An Approach to Favor Industrial Symbiosis: The Case of Waste Electrical and Electronic Equipment. Procedia Manuf. 2018, 21, 502-509. [CrossRef]

25. Cohen-Rosenthal, E. A Walk on the Human Side of Industrial Ecology. Am. Behav. Sci. 2000, 44, 245-264. [CrossRef]

26. Boons, F.; Spekkink, W.; Jiao, W. A Process Perspective on Industrial Symbiosis: Theory, Methodology, and Application. J. Ind. Ecol. 2014, 18, 341-355. [CrossRef]

27. Gibbs, D.; Deutz, P.; Proctor, A. Industrial Ecology and Eco-Industrial Development: A Potential Paradigm for Local and Regional Development? Reg. Stud. 2005, 39, 171-183. [CrossRef]

28. Belaud, J.P.; Adoue, C.; Vialle, C.; Chorro, A.; Sablayrolles, C. A Circular Economy and Industrial Ecology Toolbox for Developing an Eco-Industrial Park: Perspectives from French Policy. Clean Technol. Environ. Policy 2019, 21, 967-985. [CrossRef]

29. Cui, H.; Liu, C.; Côté, R.; Liu, W. Understanding the Evolution of Industrial Symbiosis with a System Dynamics Model: A Case Study of Hai Hua Industrial Symbiosis, China. Sustainability 2018, 10, 3873. [CrossRef]

30. Liu, C.; Ma, C.; Zhang, K. Going beyond the Sectoral Boundary: A Key Stage in the Development of a Regional Industrial Ecosystem. J. Clean. Prod. 2012, 22, 42-49. [CrossRef]

31. Lombardi, R. Non-Technical Barriers to (And Drivers for) the Circular Economy through Industrial Symbiosis: A Practical Input. Econ. Policy Energy Environ. 2017, 2017, 171-189. [CrossRef]

32. Mortensen, L.; Kørnøv, L. Critical Factors for Industrial Symbiosis Emergence Process. J. Clean. Prod. 2019, 212, 56-69. [CrossRef]

33. Valentine, S.V. Kalundborg Symbiosis: Fostering Progressive Innovation in Environmental Networks. J. Clean. Prod. 2016, 118, 65-77. [CrossRef]

34. Walls, J.L.; Paquin, R.L. Organizational Perspectives of Industrial Symbiosis: A Review and Synthesis. Organ. Environ. 2015, 28, 32-53. [CrossRef]

35. Jiao, W.; Boons, F. Toward a Research Agenda for Policy Intervention and Facilitation to Enhance Industrial Symbiosis Based on a Comprehensive Literature Review. J. Clean. Prod. 2014, 67, 14-25. [CrossRef]

36. Boons, F.; Chertow, M.R.; Park, J.; Spekkink, W.; Shi, H. Industrial Symbiosis Dynamics and the Problem of Equivalence: Proposal for a Comparative Framework. J. Ind. Ecol. 2016, 21, 938-952. [CrossRef]

37. Doménech, T.; Davies, M. The Social Aspects of Industrial Symbiosis: The Application of Social Network Analysis to Industrial Symbiosis Networks. Prog. Ind. Ecol. 2009, 6, 68-99. [CrossRef]

38. McGinnis, M.D. An Introduction to IAD and the Language of the Ostrom Workshop: A Simple Guide to a Complex Framework. Policy Stud. J. 2011, 39, 169-183. [CrossRef]

39. Branson, C.R.C. Re-Constructing Kalundborg: The Reality of Bilateral Symbiosis and Other Insights. J. Clean. Prod. 2016, 112, 4344-4352. [CrossRef]

40. Lombardi, D.R.; Laybourn, P. Redefining Industrial Symbiosis: Crossing Academic-Practitioner Boundaries. J. Ind. Ecol. 2012, 16, 28-37. [CrossRef] 
41. Mirata, M. Experiences from Early Stages of a National Industrial Symbiosis Programme in the UK: Determinants and Coordination Challenges. J. Clean. Prod. 2004, 12, 967-983. [CrossRef]

42. Heeres, R.R.; Vermeulen, W.J.V.; de Walle, F.B. Eco-Industrial Park Initiatives in the USA and the Netherlands: First Lessons. J. Clean. Prod. 2004, 12, 985-995. [CrossRef]

43. Jacobsen, N.B. Do Social Factors Really Matter When Companies Engage in Industrial Symbiosis? Prog. Ind. Ecol. 2007, 4, 440-462. [CrossRef]

44. Roberts, B.H. The Application of Industrial Ecology Principles and Planning Guidelines for the Development of Eco-Industrial Parks: An Australian Case Study. J. Clean. Prod. 2004, 12, 997-1010. [CrossRef]

45. Hewes, A.K.; Lyons, D.I. The Humanistic Side of Eco-Industrial Parks: Champions and the Role of Trust. Reg. Stud. 2008, 42, 1329-1342. [CrossRef]

46. Jensen, P.D.; Basson, L.; Hellawell, E.E.; Bailey, M.R.; Leach, M. Quantifying "Geographic Proximity": Experiences from the United Kingdom's National Industrial Symbiosis Programme. Resour. Conserv. Recycl. 2011, 55, 703-712. [CrossRef]

47. Abreu, M.C.S.D.; Ceglia, D. On the Implementation of a Circular Economy: The Role of Institutional Capacity-Building through Industrial Symbiosis. Resour. Conserv. Recycl. 2018, 138, 99-109. [CrossRef]

48. Jensen, P.D. The role of geospatial industrial diversity in the facilitation of regional industrial symbiosis. Resour. Conserv. Recycl. 2016, 107, 92-103. [CrossRef]

49. Ashton, W.S. Understanding the Organization of Industrial Ecosystems: A Social Network Approach. J. Ind. Ecol. 2008, 12, 34-51. [CrossRef]

50. Chertow, M.R.; Ashton, W.S.; Espinosa, J.C. Industrial Symbiosis in Puerto Rico: Environmentally Related Agglomeration Economies. Reg. Stud. 2008, 42, 1299-1312. [CrossRef]

51. Ashton, W.S.; Bain, A.C. Assessing the "Short Mental Distance" in Eco-Industrial Networks. J. Ind. Ecol. 2012, 16, 70-82. [CrossRef]

52. Corder, G.D.; Golev, A.; Fyfe, J.; King, S. The Status of Industrial Ecology in Australia: Barriers and Enablers. Resources 2014, 3, 340-361. [CrossRef]

53. Golev, A.; Corder, G.D.; Giurco, D.P. Barriers to Industrial Symbiosis: Insights from the Use of a Maturity Grid. J. Ind. Ecol. 2015, 19, 141-153. [CrossRef]

54. Kokoulina, L.; Ermolaeva, L.; Patala, S.; Ritala, P. Championing Processes and the Emergence of Industrial Symbiosis. Reg. Stud. 2019, 53, 528-539. [CrossRef]

55. Ceglia, D.; de Abreu, M.C.S.; Da Silva, F.J.C.L. Critical Elements for Eco-Retrofitting a Conventional Industrial Park: Social Barriers to Be Overcome. J. Environ. Manag. 2017, 187, 375-383. [CrossRef]

56. Gibbs, D. Trust and Networking in Inter-Firm Relations: The Case of Eco-Industrial Development. Local Econ. 2003, 18, 222-236. [CrossRef]

57. Branson, C.R.C. Bilaterial Industrial Symbiosis: An Assessment of Its Potential in New South Wales to Deal Sustainably with Manufacturing Waste. Ph.D. Thesis, The University of Sydney, Sydney, Australia, 2011.

58. Spekkink, W. Institutional Capacity Building for Industrial Symbiosis in the Canal Zone of Zeeland in the Netherlands: A Process Analysis. J. Clean. Prod. 2013, 52, 342-355. [CrossRef]

59. Ristola, P.; Mirata, M. Industrial Symbiosis for More Sustainable, Localised Industrial Systems. Prog. Ind. Ecol. An. Int. J. 2007, 4, 184. [CrossRef]

60. Yap, N.T.; Devlin, J.F. Explaining Industrial Symbiosis Emergence, Development, and Disruption: A Multilevel Analytical Framework. J. Ind. Ecol. 2017, 21, 6-15. [CrossRef]

61. Behera, S.K.; Kim, J.H.; Lee, S.Y.; Suh, S.; Park, H.S. Evolution of "designed" Industrial Symbiosis Networks in the Ulsan Eco-Industrial Park: "Research and Development into Business" as the Enabling Framework. J. Clean. Prod. 2012, 29-30, 103-112. [CrossRef]

62. Lehtoranta, S.; Nissinen, A.; Mattila, T.; Melanen, M. Industrial Symbiosis and the Policy Instruments of Sustainable Consumption and Production. J. Clean. Prod. 2011, 19, 1865-1875. [CrossRef]

63. Van Berkel, R.; Fujita, T.; Hashimoto, S.; Geng, Y. Industrial and Urban Symbiosis in Japan: Analysis of the Eco-Town Program 1997-2006. J. Environ. Manage 2009, 90, 1544-1556. [CrossRef] [PubMed]

64. Mathews, J.A.; Tan, H. Progress toward a Circular Economy in China: The Drivers (and Inhibitors) of Eco-Industrial Initiative. J. Ind. Ecol. 2011, 13, 435-457. [CrossRef]

65. Boons, F.; Spekkink, W.; Mouzakitis, Y. The Dynamics of Industrial Symbiosis: A Proposal for a Conceptual Framework Based upon a Comprehensive Literature Review. J. Clean. Prod. 2011, 19, 905-911. [CrossRef]

66. Velenturf, A.P.M.; Jensen, P.D. Promoting Industrial Symbiosis: Using the Concept of Proximity to Explore Social Network Development. J. Ind. Ecol. 2016, 20, 700-709. [CrossRef]

67. van Beers, D.; Corder, G.; Bossilkov, A.; Van Berkel, R. Industrial Symbiosis in the Australian Minerals Industry: The Cases of Kwinana and Gladstone. J. Ind. Ecol. 2007, 11, 55-72. [CrossRef]

68. Park, H.S.; Rene, E.R.; Choi, S.M.; Chiu, A.S.F. Strategies for Sustainable Development of Industrial Park in Ulsan, South Korea-From Spontaneous Evolution to Systematic Expansion of Industrial Symbiosis. J. Environ. Manag. 2008, 87, 1-13. [CrossRef] [PubMed]

69. Zhu, J.; Ruth, M. The Development of Regional Collaboration for Resource Efficiency: A Network Perspective on Industrial Symbiosis. Comput. Environ. Urban. Syst. 2014, 44, 37-46. [CrossRef]

70. Cronin, P.; Ryan, F.; Coughlan, M. Undertaking a Literature Review: A Step-by-Step Approach. Br. J. Nurs. 2008, 17, 38-43. [CrossRef] [PubMed] 
71. Chandler, J.; Cumpston, M.; Thomas, J.; Higgins, J.P.T.; Deeks, J.J.C.M. Introduction. In Cochrane Handbook for Systematic Reviews of Interventions Version 6.2; Higgins, J.P.T., Thomas, J., Chandler, J., Cumpston, M., Li, T., Page, M.J.W.V., Eds.; John Wiley \& Sons Ltd: Chichester, UK, 2021.

72. Hess, C.; Ostrom, E. A Framework for Analyzing the Knowledge Commons. In Understanding Knowledge as a Commons: From Theory to Practice; MIT Press: Cambridge, MA, USA, 2007.

73. Ostrom, E. Background on the Institutional Analysis and Development Framework. Policy Stud. J. 2011, 39, 7-27. [CrossRef]

74. Cole, D.H.; Epstein, G.; McGinnis, M.D. Combining the IAD and SES Frameworks. Int. J. Commons 2019, 13, 244. [CrossRef]

75. Grann, H. The Industrial Symbiosis at Kalundborg, Denmark. In The Industrial Green Game: Implications for Environmental Design and Management; National Academy Press: Washington, DC, USA, 1997; pp. 117-123. [CrossRef]

76. Bailey, R.; Bras, B.; Allen, J.K. Using Robust Concept Exploration and Systems Dynamics Models in the Design of Complex Industrial Ecosystems. Eng. Optim. 1999, 32, 33-58. [CrossRef]

77. Domenech, T.; Davies, M. Structure and Morphology of Industrial Symbiosis Networks: The Case of Kalundborg. Procedia Soc. Behav. Sci. 2011, 10, 79-89. [CrossRef]

78. Jacobsen, N.B.; Anderberg, S. Understanding the Evolution of Industrial Symbiotic Networks: The Case of Kalundborg. In Economics of Industrial Ecology: Materials, Structural Change, and Spatial Scales; MIT Press: Cambridge, MA, USA, 2005; pp. 313-336.

79. Ehrenfeld, J.; Gertler, N. Industrial Ecology in Practice: The Evolution of Interdependence at Kalundborg. J. Ind. Ecol. 1997, 1, 67-79. [CrossRef]

80. Lowe, E.a. Eco-Industrial Handbook for Asian Developing Countries. Rep. to Environ. Dep. Asian Dev. Bank 2001, $2001,1-312$.

81. Garg, S. Venture Boards: Distinctive Monitoring and Implications for Firm Performance. Acad. Manag. Rev. 2013, 38, 90-108. [CrossRef]

82. Chertow, M.R. Uncovering Industrial Symbiosis. J. Ind. Ecol. 2007, 11, 11-30. [CrossRef]

83. Desrochers, P. Cities and Industrial Symbiosis: Some Historical Perspectives and Policy Implications. J. Ind. Ecol. 2001, 5, 29-44. [CrossRef]

84. Olesen, M.P. Industrial Symbiosis in Kalundborg. VGB PowerTech 1999, 79, 52-54.

85. Chertow, M.R.; Ashton, W.S. The Social Embeddedness of Industrial Symbiosis Linkages in Puerto Rican Industrial Regions. In The Social Embeddedness of Industrial Ecology; Boons, F.A., Howard-Grenville, J., Eds.; Edward Elgar Publishing Ltd.: Cheltenham, UK; Northampton, MA, USA, 2009.

86. Nooij, S. An Ontology of Industrial Symbiosis: The Design of a Support Tool for Collaborative Industrial Symbiosis Research with as Test Cases from Tianjin Economic Development Area and Kalundborg. Master's Thesis, Delft University of Technology, Delft, The Netherlands, 2014.

87. Zaoual, A.-R.R.; Lecocq, X. Orchestrating Circularity within Industrial Ecosystems: Lessons from Iconic Cases in Three Different Countries. Calif. Manage. Rev. 2018, 60, 133-156. [CrossRef]

88. Symbiosis Center Denmark. Available online: https://symbiosecenter.dk/en/the-process/ (accessed on 23 February 2021).

89. Park, H.S. Eco-Efficient and Sustainable Urban. Infrastruture Development in Asia and Latin America-Case Study: Eco-Industrial Park in Ulsan, Republic of Korea; Economic Commission for Latin America and the Caribbean (ECLAC): Ulsan, Korea, 2008.

90. Park, H.S.; Won, J.Y. Ulsan Eco-Industrial Park: Challenges and Opportunities. J. Ind. Ecol. 2007, 11, 11-13. [CrossRef]

91. Park, H.S.; Choi, S.-M.; Lee, S.Y. Strategies for Sustainable Development of Industrial Park-Planning for Eco-Industrial Park in Ulsan, Korea. In Proceedings of the 13th Northeast Asian Conference on Environmental Cooperation, Seoul, Korea, 20-22 December 2004.

92. The World Bank Group. An. International Framework for Eco-Industrial Parks; The World Bank Group: Washington, DC, USA, 2017.

93. Kim, E.J. Greening Industrial Parks-A Case Study on South. Korea's Eco-Industrial Park Program; Global Green Growth Institute: Seoul, Korea, 2017.

94. Han, S. Memories of the City, the Old Future of Ulsan (26): Air Pollution from Industrial Complexes Chocked Students and Teachers Nearby (in Korean). Available online: http:/ /www.ksilbo.co.kr/news/articleView.html?idxno=507062 (accessed on 15 January 2021).

95. Lee, Y. Pollution Caused Damage to Agricultural Products in Ulsan Worth of KRW 1.1 Billion (in Korean). Available online: http: / / www.seoul.co.kr/news / newsView.php?id=19910128010001\&rftime=20150630\&redirect=false. (accessed on 5 January 2021).

96. Moon, T.H. Korea 's Sustainable Development Strategy. Korea Obs. 2009, 40, 85-114.

97. Park, H.S.; Behera, S.K. Role of Eco-Production in Managing Energy and Environmental Sustainability in Cities: A Lesson from Ulsan Metropolis, South Korea. In Cities and Sustainability: Issues and Strategic Pathways; Springer: New Delhi, India, 2015; pp. 1-5. [CrossRef]

98. Park, J.M.; Park, J.Y.; Park, H.S. A Review of the National Eco-Industrial Park Development Program in Korea: Progress and Achievements in the First Phase, 2005. J. Clean. Prod. 2015, 114, 33-44. [CrossRef]

99. Susur, E.; Hidalgo, A.; Chiaroni, D. The Emergence of Regional Industrial Ecosystem Niches: A Conceptual Framework and a Case Study. J. Clean. Prod. 2019, 208, 1642-1657. [CrossRef]

100. Mat, N.; Cerceau, J.; Shi, L.; Park, H.S.; Junqua, G.; Lopez-Ferber, M. Socio-Ecological Transitions toward Low-Carbon Port Cities: Trends, Changes and Adaptation Processes in Asia and Europe. J. Clean. Prod. 2016, 114, 362-375. [CrossRef]

101. MacLachlan, I. Kwinana Industrial Area: Agglomeration Economies and Industrial Symbiosis on Western Australia's Cockburn Sound. Aust. Geogr. 2013, 44, 383-400. [CrossRef]

102. van Beers, D.; Bossilkov, A.; van Berkel, R. A Regional Synergy Approach to Advance Sustainable Water Use: A Case Study Using Kwinana (Western Australia). Australas. J. Environ. Manag. 2008, 15, 149-158. [CrossRef] 
103. van Beers, D. Application of the Cleaner Production Framework to the Development of Regional Synergies in Heavy Industrial Areas: A Case Study of Kwinana (Western, Australia). Ph.D. Thesis, Curtin University of Technology, Bentley, Australia, 2009.

104. Harris, S. Industrial Symbiosis in the Kwinana Industrial Area (Western Australia). Meas. Control. 2007, 40, 239-244. [CrossRef]

105. van Beers, D.; Corder, G.D.; Bossilkov, A.; van Berkel, R. Regional Synergies in the Australian Minerals Industry: Case-Studies and Enabling Tools. Miner. Eng. 2007, 20, 830-841. [CrossRef]

106. Rosano, M.; Schianetz, K. Measuring Sustainability Performance in Industrial Parks: A Case Study of the Kwinana Industrial Area. Int. J. Sustain. Dev. 2014, 17, 261-280. [CrossRef]

107. van Beers, D. Capturing Regional Synergies in the Kwinana Industrial Area; Centre for Sustainable Resource Processing (CSRP): Bentley, Australia, 2008.

108. Kurup, B.; Stehlik, D. Towards a Model to Assess the Sustainability Implications of Industrial Symbiosis in Eco-Industrial Parks. Prog. Ind. Ecol. 2009, 6, 103-119. [CrossRef]

109. Rayner, K. Development of an Environmental Protection Policy for Air Quality at Kwinana; Environmental Protection Authority: Perth, Australia, 1992; pp. 1-42.

110. Verstegen, P. Capacity Building and Resource Exchange Kwinana Industries-A Western Australian Contribution to Industrial Ecology Examining Mechanisms for Sustainable Industrial Development. In Proceedings of the International Sustainability Conference, Fremantle, Australia, 17-19 September 2003.

111. Bossilkov, A.; Van Beers, D.; Van Behkel, R. Industrial Symbiosis as an Integrative Business Practice in Kwinana Industrial Area, Lessons Learnt and Ways Forward. In Proceedings of the 11th International Sustainable Development Research Conference, Helsinki, Finland, 6-8 June 2005.

112. Giurco, D.; Bossilkov, A.; Patterson, J.; Kazaglis, A. Developing Industrial Water Reuse Synergies in Port Melbourne: Cost Effectiveness, Barriers and Opportunities. J. Clean. Prod. 2011, 19, 867-876. [CrossRef]

113. Harris, S.; Van Berkel, R.; Kurup, B. Fostering Industrial Symbiosis for Regional Sustainable Development Outcomes. In Proceedings of the Corporate Responsibility Research Conference, Belfast, UK, 7-9 September 2008; pp. 1-21.

114. Kurup, B.R. Methodology for Capturing Environmental, Social and Economic Implications of Industrial Symbiosis in Heavy Industrial Areas. Ph.D. Thesis, Curtin University of Technology, Bentley, Australia, 2007.

115. Higham, A.; Verstegen, P. Sustainable Production and Consumption Policy Development: A Case Study from Western Australia Andrew. In The International Handbook on Environmental Technology Management; Edward Elgar Publishing Limited: Northampton, MA, USA, 2007. [CrossRef]

116. Williamson, O.E. Transaction-Cost Economics: The Governance of Contractual Relations. J. Law Econ. 1979, 22, 233-261. [CrossRef]

117. Ceglia, D. An Analysis of Instituional Dynamic for Industrial Symbiosis in the United Kingdom. Master's Thesis, Universidade Federal do Ceará, Ceará, Brazil, 2015.

118. Ostrom, E. Governing the Commons; Cambridge University Press: New York, NY, USA, 1999. [CrossRef]

119. van Beers, D.; Bossilkov, A.; Lund, C. Development of Large Scale Reuses of Inorganic By-Products in Australia: The Case Study of Kwinana, Western Australia. Resour. Conserv. Recycl. 2009, 53, 365-378. [CrossRef]

120. Watkins, G.; Husgafvel, R.; Pajunen, N.; Dahl, O.; Heiskanen, K. Overcoming Institutional Barriers in the Development of Novel Process Industry Residue Based Symbiosis Products-Case Study at the EU Level. Miner. Eng. 2013, 41, 31-40. [CrossRef] 